\title{
Determination of the multiple-scattering correction factor and its cross-sensitivity to scattering and wavelength dependence for different AE33 Aethalometer filter tapes: a multi-instrumental approach
}

\author{
Jesús Yus-Díez ${ }^{1,2}$, Vera Bernardoni ${ }^{3}$, Griša Močnik ${ }^{4,5}$, Andrés Alastuey ${ }^{1}$, Davide Ciniglia ${ }^{3}$, Matic Ivančǐč ${ }^{6}$, \\ Xavier Querol $^{1}$, Noemí Perez ${ }^{1}$, Cristina Reche ${ }^{1}$, Martin Rigler ${ }^{6}$, Roberta Vecchi ${ }^{3}$, Sara Valentini ${ }^{3}$, and \\ Marco Pandolfi ${ }^{1}$ \\ ${ }^{1}$ Institute of Environmental Assessment and Water Research (IDAEA), CSIC, C/Jordi Girona 18-26, 08034, Barcelona, Spain \\ ${ }^{2}$ Grup de Meteorologia, Departament de Física Aplicada, Universitat de Barcelona, C/Martí i Franquès, 1, \\ 08028, Barcelona, Spain \\ ${ }^{3}$ Dipartimento di Fisica "Aldo Pontremoli”, Università degli Studi di Milano \& INFN Milano, via Celoria 16, \\ 20133 Milan, Italy \\ ${ }^{4}$ Center for Atmospheric Research, University of Nova Gorica, Vipavska 11c, 5270 Ajdovščina, Slovenia \\ ${ }^{5}$ Department of Condensed Matter Physics, Jožef Stefan Institute, Jamova 39, 1000 Ljubljana, Slovenia \\ ${ }^{6}$ Aerosol d.o.o., Kamniška 39A, 1000 Ljubljana, Slovenia
}

Correspondence: Jesús Yus-Díez (jesus.yus@idaea.csic.es)

Received: 17 February 2021 - Discussion started: 29 March 2021

Revised: 19 July 2021 - Accepted: 25 August 2021 - Published: 1 October 2021

\begin{abstract}
Providing reliable observations of aerosol particles' absorption properties at spatial and temporal resolutions suited to climate models is of utter importance to better understand the effects that atmospheric particles have on climate. Nowadays, one of the instruments most widely used in international monitoring networks for in situ surface measurements of light absorption properties of atmospheric aerosol particles is the multi-wavelength dual-spot Aethalometer, AE33. The AE33 derives the absorption coefficients of aerosol particles at seven different wavelengths from the measurements of the optical attenuation of light through a filter where particles are continuously collected. An accurate determination of the absorption coefficients from the AE33 instrument relies on the quantification of the non-linear processes related to the sample collection on the filter. The multiple-scattering correction factor $(C)$, which depends on the filter tape used and on the optical properties of the collected particles, is the parameter with both the greatest uncertainty and the greatest impact on the absorption coefficients derived from the AE33 measurements.
\end{abstract}

Here we present an in-depth analysis of the AE33 multiple-scattering correction factor $C$ and its wavelength dependence for two different and widely used filter tapes, namely the old, and most referenced, TFE-coated glass, or M8020, filter tape and the currently, and most widely used, M8060 filter tape. For performing this analysis, we compared the attenuation measurements from AE33 with the absorption coefficients measured with different filter-based techniques. On-line co-located multi-angle absorption photometer (MAAP) measurements and off-line PP_UniMI polar photometer measurements were employed as reference absorption measurements for this work. To this aim, we used data from three different measurement stations located in the north-east of Spain, namely an urban background station (Barcelona, BCN), a regional background station (Montseny, MSY) and a mountaintop station (Montsec d'Ares, MSA). The median $C$ values (at $637 \mathrm{~nm}$ ) measured at the three stations ranged between 2.29 (at BCN and MSY, lowest 5th percentile of 1.97 and highest 95th percentile of 2.68) and 2.51 (at MSA, lowest 5th percentile of 2.06 and highest 95 th percentile of 3.06 ). The analysis of the cross-sensitivity to 
scattering, for the two filter tapes considered here, revealed a large increase in the $C$ factor when the single-scattering albedo (SSA) of the collected particles was above a given threshold, up to a 3 -fold increase above the average $C$ values. The SSA threshold appeared to be site dependent and ranged between 0.90 to 0.95 for the stations considered in the study. The results of the cross-sensitivity to scattering displayed a fitted constant multiple-scattering parameter, $C_{\mathrm{f}}$, of 2.21 and 1.96 , and a cross-sensitivity factor, $m_{\mathrm{s}}$, of $1.8 \%$ and $3.4 \%$ for the MSY and MSA stations, respectively, for the TFEcoated glass filter tape. For the M8060 filter tape, $C_{\mathrm{f}}$ values of $2.50,1.96$ and 1.82 and $m_{\mathrm{s}}$ values of $1.6 \%, 3.0 \%$ and $4.9 \%$ for the BCN, MSY and MSA stations, respectively, were obtained. SSA variations also influenced the spectral dependence of $C$, which showed an increase with wavelength when SSA was above the site-dependent threshold. Below the SSA threshold, no statistically significant dependence of $C$ on the wavelength was observed. For the measurement stations considered here, the wavelength dependence of $C$ was to some extent driven by the presence of dust particles during Saharan dust outbreaks that had the potential to increase the SSA above the average values. At the mountaintop station, an omission of the wavelength dependence of the $C$ factor led to an underestimation of the absorption Ångström exponent (AAE) by up to $12 \%$. Differences in the absorption coefficient determined from AE33 measurements at BCN, MSY and MSA of around 35\%-40\% can be expected when using the site-dependent experimentally obtained $C$ value instead of the nominal $C$ value. Due to the fundamental role that the SSA of the particles collected on the filter tape has in the multiple-scattering parameter $C$, we present a methodology that allows the recognition of the conditions upon which the use of a constant and wavelength-independent $C$ is feasible.

\section{Introduction}

Atmospheric aerosol particles play an important role in the Earth's radiative balance directly by scattering and absorbing solar and terrestrial radiation and indirectly by acting as cloud condensation nuclei. Large uncertainties still exist regarding the effects that atmospheric particles have on climate (Myhre et al., 2013). In fact, the aerosol-radiation interaction depends on aerosol properties such as aerosol size distribution, mixing state and refractive index, among others (e.g. Bond et al., 2013). Globally, aerosols have helped to reduce the warming effect from greenhouse gases because of their net cooling effect on climate (Myhre et al., 2013). However, this influence is likely to be reduced over the coming decades as air pollution measures are implemented around the world (Samset et al., 2018), as is already the case in parts of Europe and North America (Collaud Coen et al., 2020). Therefore, in order to properly constrain global models, it is necessary to better characterize the atmospheric absorption by aerosols from observations. Among the atmospheric aerosols, black carbon (BC) stands out as phenomenologically different, being the most efficient light-absorbing aerosol component and being responsible for the second-most-important contribution to positive climate forcing after carbon dioxide (Myhre et al., 2013). However, there are still large uncertainties related to the radiative forcing of $\mathrm{BC}$ particles. In fact, the climate forcing potential of $\mathrm{BC}$ is influenced by $\mathrm{BC}$ properties which are strongly source and site dependent (IPCC, 2001; Ramanathan et al., 2001; Kirchstetter et al., 2004a; Ramanathan and Carmichael, 2008; Myhre et al., 2013; Bond et al., 2013; Liu et al., 2015). In addition to BC, atmospheric absorption by aerosol particles is also driven by specific organic compounds (e.g. from incomplete combustion, biomass smoldering, and secondary and biogenic sources) often referred to as brown carbon $(\mathrm{BrC})$ and by mineral dust (e.g. Alfaro et al., 2004). Unlike BC, which absorbs radiation in a wide range of wavelengths (from UV to infrared) with a wavelength-independent refractive index, the $\mathrm{BrC}$ and mineral dust refractive index increases at shorter wavelengths, close to the UV range (Kirchstetter et al., 2004a; Andreae and Gelencsér, 2006; Bergstrom et al., 2007; Laskin et al., 2015; Cappa et al., 2019). Therefore, having at one's disposal accurate absorption measurement techniques is crucial to determining particles' light absorption which can afterwards be used in climate projections (Mengis and Matthews, 2020; Wang et al., 2020). Moreover, there is also the need for standard aerosol particles to use as a reference for the quality assurance of absorption measurements, such as the recently developed flame-generated soot in Ess and Vasilatou (2019).

There are three main approaches in the literature to determining aerosol particles' light absorption: by measuring the suspended particles in a cell, e.g. with photo-thermal interferometry or photo-acoustic techniques, and by either on-line or off-line filter-based photometer methods (e.g. Lin et al., 1973; Terhune and Anderson, 1977; Hansen et al., 1984; Stephens et al., 2003; Moosmüller et al., 2009; Ajtai et al., 2010; Vecchi et al., 2014). Among the indirect methods for measuring absorption, the "subtraction method", which does not rely on a filter, calculates the absorption from the difference between extinction and scattering by suspended particles (Singh et al., 2014). However, this method can lead to large errors at large single-scattering albedo (SSA) values when the extinction is dominated by scattering (Onasch et al., 2015). On-line measurement methodologies based on particle suspension, such as photo-acoustic spectroscopy (PAS) (Ajtai et al., 2010), have the advantage of measuring directly the absorption by particles suspended in a sampling cell avoiding filter-based artefacts. However, in the case of photo-acoustic spectroscopy measurements, the heating of the sample and the evaporation of coating materials on the sample may lead to higher detection limit and artefacts impairing the measurement accuracy (Lack et al., 2006; Linke et al., 2016). The photo-thermal interferometry (PTI) is an absorption measurement technique originally developed for 
measurements of trace gases that has also been applied to aerosol measurements (Lee and Moosmüller, 2020; Visser et al., 2020). However, the aforementioned techniques have so far proved difficult to deploy in a field setting, thus limiting their broader use in international measurement networks. Filter-based instruments (either on-line or off-line) rely on the sampling of aerosol particles collected in a filter matrix and on the measurement of the resulting change in light intensity with a photometer, either in the transmittance (Hansen et al., 1984; Bond et al., 1999; Drinovec et al., 2015) or in both transmittance and reflectance (Petzold and Schönlinner, 2004). This method is affected by artefacts resulting mainly from the effects that the filter has on the measurements. Off-line in-house-made filter-based polar photometers, which measure both transmittance and reflectance, are deployed at some research centres. Examples are the MWAA (multi-wavelength absorption analyser) deployed at the University of Genoa (Massabò et al., 2013) and the PP_UniMI polar photometer deployed at the University of Milan (Vecchi et al., 2014; Bernardoni et al., 2017). These methods can perform accurate absorption measurements by increasing the number of measuring angles (Massabò et al., 2013; Vecchi et al., 2014; Bernardoni et al., 2017), thus allowing an accurate determination of the filter artefacts.

The main advantage of the on-line filter-based methods is that these techniques are easy to use, allow for unattended operation, are relatively inexpensive and provide real-time data. For these reasons, these methods are widely used in international networks such as the Global Atmosphere Watch (GAW, World Meteorological Organization) and the European Aerosols, Clouds and Trace Gases Research Infrastructure (ACTRIS; https://www.actris.eu, last access: 20 September 2021). The most used filter-based instruments are the Aethalometer (Hansen et al., 1984; Drinovec et al., 2015), the particle soot absorption photometer (PSAP; Bond et al., 1999), the continuous light absorption photometer (CLAP; Ogren et al., 2017) and the multi-angle absorption photometer (MAAP; Model 5012, Thermo Fisher Scientific Inc., USA; Petzold and Schönlinner, 2004). The measured mass concentration of light-absorbing carbonaceous aerosols inferred via optical attenuation of light is referred to as equivalent BC (eBC; Petzold et al., 2013). The main artefacts affecting the light absorption measurements of these instruments are the multiple light scattering within the filter, the filter loading effect and the particle scattering correction (Liousse et al., 1993; Bond et al., 1999; Weingartner et al., 2003; Schmid et al., 2006; Collaud Coen et al., 2010; Lack et al., 2014). Algorithms for correcting these artefacts have been applied and their efficacy tested over the years (Weingartner et al., 2003; Arnott et al., 2005; Schmid et al., 2006; Virkkula et al., 2007; Collaud Coen et al., 2010; Virkkula et al., 2015). Currently, due to the described limitations of the filter-based photometers and other in situ methods, no reference technique for measuring near-real-time aerosol parti- cles' light absorption is available (Petzold et al., 2013; Lack et al., 2014).

The filter loading effect consists in the accumulation of particles and the consequent loss of sensitivity of the instrument with an increasing particle load (Bond et al., 1999; Weingartner et al., 2003; Lack et al., 2008; Moosmüller et al., 2009). The cross-sensitivity to scattering is the consequence of the multiple light scattering within the filter fibres and between particles and fibres; thus it is largely dependent on the single-scattering albedo of the deposited aerosols. For the older Aethalometer model (AE31) the filter loading effect has been thoroughly studied, and different methods for its quantification have been suggested. These methods use for example the discontinuity between the eBC concentration measurements before and after a filter spot is changed (Weingartner et al., 2003; Virkkula et al., 2007) or the relationship between the eBC concentration and light attenuation (Park et al., 2010; Segura et al., 2014; Drinovec et al., 2015) to correct for the filter loading effect. For the AE33 model the loading effect is corrected on-line using dual-spot technology (Drinovec et al., 2015). In addition, the different physical and chemical properties of the collected particles influence particle optical properties, such as the backscatter fraction and the single-scattering albedo (SSA), thus also affecting the multiple scattering of the collected particles and the filter loading effect (Weingartner et al., 2003; Lack et al., 2008; Virkkula et al., 2015; Drinovec et al., 2017). Among the online filter-based instruments, the multi-angle absorption photometer (MAAP) also uses the measurements of light scattered by the blank and loaded filter in order to take into account both the loading effect and the aerosol particles' multiple scattering. Consequently, the MAAP directly provides particle absorption coefficients similar to those obtained with other types of instruments (e.g. PAS instruments; Petzold and Schönlinner, 2004; Petzold et al., 2005).

The multi-wavelength dual-spot Aethalometer software (AE33, Magee Scientific, Aerosol d.o.o. - Drinovec et al., 2015) corrects the loading effect on-line and directly implements the use of a correction factor $(C)$ related to the multiple scattering within the filter matrix to convert the measured attenuation to an absorption coefficient. This $C$ factor is generally assumed a priori, but it can be experimentally determined by using independent absorption measurements or by comparisons with other filter photometers (e.g. Weingartner et al., 2003; Arnott et al., 2005; Drinovec et al., 2015; Backman et al., 2017). For previous filter tapes and Aethalometer versions different values of the multiple-scattering parameter have been reported: for the AE31 quartz filter Weingartner et al. (2003) proposed a value of 2.14 which later on was recommended to be 3.5, i.e. larger by a factor of 1.64 (Müller, 2015; World Meteorological Organization, 2016); for the AE33 Drinovec et al. (2015) found a $C$ value of 1.57 for the Pallflex Teflon-coated glass fibre (TFE-coated glass, also known as M8020), which, after re-normalization using the factor 1.64 , resulted in $C=2.57$. Moreover, differ- 
ent experimental $C$-factor values have been obtained ranging between 2.57-4.24 (Müller et al., 2011b; Drinovec et al., 2020; Laing et al., 2020; Valentini et al., 2020a; Bernardoni et al., 2020). In addition, the quartz filter for the AE31 and the TFE-coated glass filter for the AE33 have been found to feature a cross-sensitivity to scattering, $m_{\mathrm{s}}$, ranging between $1 \%$ and 3\% (Müller et al., 2011a; Müller, 2015; Drinovec et al., 2015; Zhang et al., 2018; Corbin et al., 2018; Laing et al., 2020; Drinovec et al., 2020). However, to the best of our knowledge, so far, no in situ ambient measurements have been used for a detailed characterization of the new recommended M8060 filter tape. Moreover, no sensitivity studies of the cross-sensitivity to scattering of the $C$ factor have been reported and only very few studies have dealt with the wavelength dependence of $C$ for either the previous or the current filter tapes.

The recent comparison between the MAAP and the offline PP_UniMI polar photometer carried out by Valentini et al. (2020b) pointed to a possible measurement bias of the MAAP absorption coefficients. It is well established that the MAAP, although limited to one measuring wavelength, is the most accurate filter-based on-line method available for the determination of the absorption coefficient (Petzold et al., 2005; Sheridan et al., 2005; Andreae and Gelencsér, 2006; Müller et al., 2011a). Therefore, it is often taken as the reference in inter-comparison exercises with other instruments, such as the AE33, e.g. in Backman et al. (2017). The discrepancy between the MAAP and PP_UniMI reported by Valentini et al. (2020b) was mainly attributed to the value of the fraction of backscattered radiation set in the MAAP algorithm and directly measured by PP_UniMI due to its high angular resolution which scans the whole scattering plane (a resolution of $0.4^{\circ}$ in the scattering angle range $0-173^{\circ}$ ). Valentini et al. (2020b) also reported no differences between the MAAP and PP_UniMI when PP_UniMI was used with the same assumptions as those used in the MAAP (PaM as defined in Valentini et al., 2020b).

The main objective of this study is to characterize the $C$ factor for different filter tapes used in AE33 instruments including the currently used M8060. To this aim, we compared the absorption coefficient measurements from the offline PP_UniMI polar photometer with the on-line MAAP and AE33 measurements performed at three measurement stations (urban background, Barcelona, BCN; regional background, Montseny, MSY; and mountaintop, Montsec d'Ares, MSA) in the western Mediterranean Basin (WMB). The novelty of this study relies on the seasonal and diel variation analysis of the $C$ factor and, especially, on the exploration of the cross-sensitivity to scattering of $C$ and its relationship with the intensive optical properties of the collected particles at the three sites. This analysis allowed us to obtain both the multiple-scattering parameter, $C_{\mathrm{f}}$, and the cross-sensitivity to scattering, $m_{\mathrm{s}}$, constants for the M8060 filter currently used by the AE33 Aethalometers. Moreover, we compared the results for the M8060 filter tape with the previously used
TFE-coated glass filter tape (T60A20, also referred to as M8020) (Weingartner et al., 2003; Arnott et al., 2005; Drinovec et al., 2015). As previously mentioned, the comparison between PP_UniMI and the MAAP was reported in Valentini et al. (2020b) where data from the BCN and MSY stations were also used to evaluate the performances of PP_UniMI vs. the MAAP. One of the main objectives of this study was to use the multi-wavelength absorption coefficient measurements from the off-line polar photometer extrapolated to the seven AE33 measurement wavelengths to study the wavelength dependence of the AE33 $C$ factor at the three measurement sites.

\section{Methodology}

\subsection{Measurement sites}

Aerosols measurements were performed at Barcelona (BCN; urban background; $41^{\circ} 23^{\prime} 24.01^{\prime \prime} \mathrm{N}, 2^{\circ} 6^{\prime} 58.06^{\prime \prime} \mathrm{E}$; $80 \mathrm{~m}$.a.s.1.), Montseny (MSY; regional background; $41^{\circ} 46^{\prime} 46^{\prime \prime} \mathrm{N}, 2^{\circ} 21^{\prime} 29^{\prime \prime} \mathrm{E} ; 720 \mathrm{~m}$ a.s.l.) and Montsec d'Ares (MSA; mountaintop; $42^{\circ} 3^{\prime} 5^{\prime \prime} \mathrm{N}, 0^{\circ} 43^{\prime} 46^{\prime \prime} \mathrm{E} ; 1570 \mathrm{~m}$ a.s.l.) monitoring supersites (NE Spain). As shown later, these stations are characterized by aerosols with different physical and chemical properties that influenced the differences obtained in the $C$ values. A detailed characterization of the three measurement stations can be found in previous works (e.g. Querol et al., 2001; Rodriguez et al., 2001; Reche et al., 2011, for BCN; Pérez et al., 2008; Pey et al., 2009; Pandolfi et al., 2011, for MSY; Pandolfi et al., 2014a; Ripoll et al., 2014; Ealo et al., 2016, for MSA). Briefly, the BCN station is located within the Barcelona metropolitan area of nearly 4.5 million inhabitants at a distance of about $5 \mathrm{~km}$ from the coast. The MSY station is located in a hilly and densely forested area, $50 \mathrm{~km}$ to the N-NE of Barcelona and $25 \mathrm{~km}$ from the Mediterranean coast. The MSA station is located in a remote high-altitude emplacement on the southern side of the Pre-Pyrenees at the Montsec Range, $140 \mathrm{~km}$ to the NW of Barcelona and $140 \mathrm{~km}$ to the WNW of MSY. These supersites are part of the Catalonian Atmospheric Pollution Monitoring and Forecasting Network and of the ACTRIS and GAW networks. Aerosol optical properties at the three sites were measured following standard protocols (WMO/GAW, 2016).

The area of study is characterized by high concentrations of both primary and secondary aerosols, especially in summer (Rodríguez et al., 2002; Dayan et al., 2017; Rivas et al., 2020; Brean et al., 2020) from diverse emission sources. Anthropogenic emissions from road traffic, industry, agriculture and maritime shipping, among others, strongly contribute to the air quality impairment in this region (Querol et al., 2009b; Amato et al., 2009; Pandolfi et al., 2014b). Moreover, the Mediterranean Basin is also highly influenced by natural sources, such as mineral dust from African deserts and smoke 
from forest fires (Bergametti et al., 1989; Querol et al., 1998; Rodriguez et al., 2001; Lyamani et al., 2006; Mona et al., 2006; Koçak et al., 2007; Kalivitis et al., 2007; Querol et al., 2009b; Schauer et al., 2016; Ealo et al., 2016; Querol et al., 2019, among others).

\subsection{Aerosol characterization}

\subsubsection{Aerosol absorption and $\mathrm{eBC}$ measurements}

The on-line aerosol absorption coefficient, $b_{\mathrm{abs}}$, was measured at the three sites with a multi-angle absorption photometer (MAAP; Model 5012, Thermo Fisher Scientific Inc., USA; Petzold and Schönlinner, 2004). This instrument derives the absorption coefficient at $637 \mathrm{~nm}$ (Müller et al., 2011a) and eBC concentration using a radiative transfer model from the measurements of transmission of light through the filter tape and backscattering of light at two different angles. Black carbon, eBC, and attenuation measurements, $b_{\text {atn }}$, were also performed with the AE33 multiwavelength Aethalometer (model AE33, Magee Scientific, Aerosol d.o.o.; Drinovec et al., 2015). The AE33 is based on the measurement at seven different wavelengths (370, $470,520,590,660,880$ and $950 \mathrm{~nm}$ ) of the transmission of light through two sample spots with different flows and particle loading relative to the reference spot. It derives the eBC concentration and the attenuation coefficients by applying Eqs. (1) and (2), respectively, following Drinovec et al. (2015):

$\mathrm{eBC}=\frac{S \cdot\left(\Delta \mathrm{ATN}_{1} / 100\right)}{F_{1}(1-\zeta) \cdot \sigma_{\mathrm{abs}} \cdot C\left(1-k \Delta \mathrm{ATN}_{1}\right) \cdot \Delta t}$,

$b_{\text {atn }}=\frac{S \cdot\left(\Delta \mathrm{ATN}_{1} / 100\right)}{F_{1}(1-\zeta) \cdot\left(1-k \Delta \mathrm{ATN}_{1}\right) \cdot \Delta t}$,

where $S$ is the filter surface area loaded with the sample; $F_{1}$ the volumetric flow of spot $1 ; \zeta$ the lateral airflow leakage; $\sigma_{\mathrm{abs}}$ the mass-absorption cross-section; $k$ the loading factor parameter; and $\triangle \mathrm{ATN}_{1}$ the variation in attenuation of light of the filter tape loaded with the sample of spot $1, \mathrm{ATN}_{1}$, during the measurement timestamp $\Delta t$.

The Aethalometer absorption coefficient can be derived by dividing the attenuation coefficient (Eq. 2) by the multiplescattering parameter $C$ of the filter tape:

$b_{\mathrm{abs}}=\frac{b_{\mathrm{atn}}}{C}$.

Off-line multi-wavelength particle absorption coefficients were obtained using the PP_UniMI polar photometer (Vecchi et al., 2014; Bernardoni et al., 2017) measurements on the MAAP filter spots. A total of 85 filter spots collected at BCN in the period October 2018-June 2019, 126 filter spots collected at MSY between June and December 2018 (Valentini et al., 2020b), and 122 filter spots collected at MSA between June and November 2018 were analysed. The time elapsed between the MAAP measurements and the MAAP spots analysis with PP_UniMI in Milan varied between 1 year and 1 month. Once selected and cut, each MAAP spot was stored in a petri dish in a fridge and then sent to Milan. We assumed that there were no major particle losses affecting the measured optical properties, although some volatile compounds could have been evaporated over the period. PP_UniMI measures the transmitted and scattered radiation at four wavelengths $(405,532,635$ and $780 \mathrm{~nm})$ in a range of scattering angles from 0 to $173^{\circ}$ with a resolution down to $0.4^{\circ}$ and applies a radiative transfer model to derive the absorption coefficients. The PP_UniMI working principle and the detailed analysis of the inter-comparison between the MAAP and PP_UniMI for different measurement sites, including BCN and MSY, were reported in Vecchi et al. (2014), Bernardoni et al. (2017) and Valentini et al. (2020b). As mentioned before, in these studies no differences were observed between the MAAP and PP_UniMI when the latter was used as a MAAP (PaM), i.e. using a data inversion with similar assumptions to those performed in the MAAP.

Here we obtain the wavelength-dependent attenuation coefficients $b_{\text {atn }}(\lambda)$ derived exclusively from the AE33 measurements by multiplying the eBC concentrations provided by the $\mathrm{AE} 33$ (Eq. 4) by the default wavelength-independent instrumental filter constant $C_{0}$ from the AE33 setup file (1.57 for the TFE-coated glass fibre tape T60A20, also referred to as M8020, and 1.39 for the M8060 filter tape):

$$
\begin{aligned}
b_{\mathrm{atn}}(\lambda) & =\mathrm{eBC}(\lambda) \cdot \sigma_{\mathrm{abs}}(\lambda) \cdot C_{0} \\
& =\frac{S}{F} \frac{\Delta \operatorname{ATN}(\lambda)}{\Delta t} \cdot f(\mathrm{ATN}, \lambda),
\end{aligned}
$$

where $f(\mathrm{ATN}, \lambda)$ is the function which contains all the corrections, i.e. filter loading and leakage, which are performed by the AE33 for each wavelength (Drinovec et al., 2015). Note that the new filter tape M8060 structurally differs from the old filter tape M8020 in filter fibre material, thickness and density, thus leading to different $C_{0}$ values (details can be found in the following online document from Magee Scientific: https://mageesci.com/tape/Magee_Scientific_Filter_ Aethalometer_AE_Tape_Replacement_discussion.pdf, last access: 20 September 2021).

Then, we determine the average and seasonal multiplescattering factor $C$ both as the ratio between the AE33 attenuation coefficients and the absorption coefficients $b_{\mathrm{abs}}(\lambda)$ measured by the MAAP and PP_UniMI (Eq. 5) and also by applying a Deming regression between the AE33 attenuation coefficients and the MAAP absorption coefficients for the overall average values for each filter tape.

$C(\lambda)=\frac{b_{\text {atn }}(\lambda)}{b_{\text {abs }}(\lambda)}$

This value of the multiple-scattering parameter $C(\lambda)$ is the value derived from the experimental comparison of different instruments, contrasting the default instrumental constant 
value $C_{0}$. The data at the $\mathrm{BCN}$ station were available from between 2016 and 2020; at MSY and MSA data were measured from 2013 to 2020. Different AE33 filter tapes were used during these periods at the three stations as shown in Fig. S1 in the Supplement.

\subsubsection{Aerosol scattering measurements}

On-line particle total scattering $\left(b_{\mathrm{sp}}\right)$ and hemispheric backscatter $\left(b_{\mathrm{bsp}}\right)$ coefficients were measured on-line at the three sites with LED-based integrating nephelometers (Aurora 3000, Ecotech Pty Ltd, Knoxfield, Australia) operating at three wavelengths $(450,525$ and $635 \mathrm{~nm})$. Calibration of the nephelometers was performed three times per year using $\mathrm{CO}_{2}$ as the span gas, and zero adjusts were performed once per day using internally filtered particle-free air. The RH threshold was set by using a processor-controlled automatic heater inside the Aurora 3000 nephelometer to ensure a sampling RH of less than $40 \%$ (World Meteorological Organization, 2016). $\sigma_{\mathrm{sp}}$ coefficients were corrected for nonideal illumination of the light source and for truncation of the sensing volumes following the procedure described in Müller et al. (2011b).

\subsection{Data treatment and conceptual model}

The different analyses were performed considering the absorption coefficients provided by either the MAAP or PP_UniMI as reference absorption measurements depending on either time resolution and coverage or the measurement availability at several wavelengths. The AE33 and MAAP data (provided with a high temporal resolution) were used to study the seasonal variations and the cross-sensitivity to scattering of the $C$ factor. The AE33 and PP_UniMI data (provided with a low temporal resolution but at different wavelengths) were used to determine the wavelength dependence of the $C$ factor.

\subsubsection{Average and seasonal value analysis and cross-sensitivity to scattering analysis}

As previously mentioned, the seasonal analysis of the $C$ factor, analysis of its average values and the study of its crosssensitivity to scattering were performed using the long-term high-time-resolution dataset from the MAAP and AE33 measurements at the three measurement sites. For this, we applied Eq. (5) using the absorption coefficient from the MAAP and the AE33 attenuation coefficient extrapolated to the $637 \mathrm{~nm}$ wavelength of the MAAP through the Ångström exponent obtained from the AE33 measurements at seven wavelengths.

The cross-sensitivity to scattering which, as shown later, can strongly affect the $C$-factor values is neglected in AE33 applications where it is generally assumed that the measured light attenuation is only due to the absorption of light by the collected particles (Eqs. 1 and 2). Moreover, it is also generally assumed that the multiple scattering by particles is sample independent, or constant, and can be taken into account by introducing the multiple-scattering correction factor $C$ (Drinovec et al., 2015). However, this assumption is a first approximation, since the attenuation of transmitted light is also due to the scattering of light by the collected particles (Bond et al., 1999; Arnott et al., 2005). Taking this dependence into account and following Arnott et al. (2005), we parameterized the light attenuation coefficient as

$b_{\mathrm{atn}}=\frac{S}{F} \frac{\Delta \mathrm{ATN}}{\Delta t} \cdot f(\mathrm{ATN})+m_{\mathrm{s}} \cdot b_{\mathrm{sp}}$

to obtain the relationship between the absorption, attenuation and scattering coefficients:

$b_{\mathrm{abs}}=\frac{b_{\mathrm{atn}}}{C_{\mathrm{f}}}-m \cdot b_{\mathrm{sp}}$.

The cross-sensitivity to scattering, which is denoted by the constant $m_{\mathrm{s}}$, is related to $m$ through $m=m_{\mathrm{s}} / C_{\mathrm{f}}$. Here $C_{\mathrm{f}}$ refers to the multiple-scattering filter parameter, that is a value (possibly wavelength dependent) that depends only on filter properties. If we rearrange Eq. (7) by expressing the scattering coefficient through the single-scattering albedo, we obtain the dependence of the absorption as a function of SSA (Eq. 8), similarly to Eq. (17) in Schmid et al. (2006). The measured multiple parameter, $C$, affected by the crosssensitivity to scattering can be expressed as shown in Eq. (9).

$$
\begin{gathered}
b_{\mathrm{abs}}=\frac{b_{\mathrm{atn}}}{C_{\mathrm{f}}} \cdot \frac{1}{1+m \cdot \frac{\mathrm{SSA}}{1-\mathrm{SSA}}} \\
C=C_{\mathrm{f}}\left(1+m \cdot \frac{\mathrm{SSA}}{1-\mathrm{SSA}}\right) \\
=C_{\mathrm{f}}+m_{\mathrm{s}} \cdot \frac{\mathrm{SSA}}{1-\mathrm{SSA}}
\end{gathered}
$$

The effective multiple-scattering parameter, $C$, depends on the physical properties of collected particles. By comparing data from different instruments (AE33, MAAP and nephelometer) we were able to parameterize the cross-sensitivity of $C$ to scattering (Eq. 8). Equation (9) shows that the actual AE33 cross-sensitivity to scattering is more pronounced when the measured aerosol particles have higher SSA, whereas for particles with lower SSA Eq. (9) converges to Eq. (5).

By analysing the dependency of the effective multiplescattering parameter $C$ on the SSA, we obtained the experimental-fit constants $\left(C_{\mathrm{f}}\right.$ and $\left.m_{\mathrm{S}}\right)$ that describe the relationship between $C$ and SSA. Furthermore, we will present in Sect. 3.1 how the cross-sensitivity to scattering of $C$ depended on some intensive aerosol particle optical properties that strongly depend on aerosol particle size distribution and chemical composition (Figs. S3-S5).

The AE33 data treatment applied to obtain the $C$ seasonality and the cross-sensitivity to scattering included a preprocess filtering method following the approach suggested in 
Springston and Sedlacek (2007) and Backman et al. (2017). This filtering method consists in setting a threshold value for the measured attenuation variation, $\Delta \mathrm{ATN}_{1}$, that is high enough for the signal-to-noise ratio to be large; herein we have used a fixed value of 0.01 . As can be deduced from Eq. (1), the faster the fixed $\Delta \mathrm{ATN}_{1}$ is reached, the shorter the period $\Delta t$, implying therefore a higher eBC concentration value during the same period. The method we employed determines the period at which the $\triangle \mathrm{ATN}_{1}$ step is reached and recalculates the $\mathrm{eBC}$ concentration for this $\Delta t$. As a consequence of this $\mathrm{eBC}$ recalculation, we filtered out the noise resulting from very small values close to the detection limit of the instrument while maintaining the higher $\mathrm{eBC}$ values measured without introducing a bias into the measurements as is the case when averaging. With the aim to study the seasonality of the $C$ factor and its cross-sensitivity to scattering, we averaged $b_{\text {abs,MAAP }}$ and $b_{\text {sp }}$ coefficients to match the corresponding AE33 variable timestamp, $\Delta t$, which ranged between approximately 3 and $14 \mathrm{~min}$ (see Fig. S2). Moreover, the time granularity of the measurements varied between 1 and $5 \mathrm{~min}$, depending on the software used for data logging (see Table S1 in the Supplement). Given the length of the measurement periods, we assumed that the AE33 filter tapes considered here were characterized under a wide range of aerosol particle properties typically observed at the measurement stations and that the non-simultaneity of AE33 measurements with the two filter tapes did not prevent the comparison between the obtained $C$.

\subsubsection{Wavelength dependence analysis}

To study the wavelength dependence of the $C$ factor we compared the absorption coefficients at several wavelengths measured with PP_UniMI with the attenuation coefficients obtained from the AE33 (Eq. 5). Since the off-line PP_UniMI measurements were performed on the MAAP spots, the measured attenuation and scattering coefficients from AE33 and the nephelometer, respectively, were averaged over the timestamp of each one of the selected MAAP spots. The absorption coefficients from PP_UniMI were interpolated and extrapolated to the seven AE33 wavelengths using the attenuation Ångström exponent, obtained through a log-log fit from the PP_UniMI absorption measurements.

Valentini et al. (2020b) reported that the MAAP overestimates the absorption coefficient compared to PP_UniMI. For BCN and MSY Valentini et al. (2020b) reported a MAAP overestimation of $18 \%$ and $21 \%$, respectively. By applying the same methodology as in Valentini et al. (2020b) we obtained a difference between the MAAP and PP_UniMI for MSA of $19 \%$ (Fig. A1), similar to the biases obtained for BCN and MSY. For this reason, Valentini et al. (2020b) also studied the comparison between the MAAP and PP_UniMI using the same assumptions for the PP_UniMI data inversion as those performed in the MAAP (PaM approach) and reported a $1: 1$ correlation between the two instruments. Given that most of the Aethalometer $C$ values reported in the literature were obtained by comparing AE33 attenuation measurements and MAAP absorption measurements, we also report here the median $C$ values obtained comparing the AE33 with PP_UniMI (Table S2) and with PaM (Table S3).

\section{Results}

\subsection{Multiple-scattering parameter cross-sensitivity to scattering}

The cross-sensitivity to scattering of the $C$ factor at the three stations was obtained by analysing the relationship between the multiple-scattering parameter $C$ (at $637 \mathrm{~nm}$ ) and the measured SSA (Eq. 9).

The SSA was obtained independently at $637 \mathrm{~nm}$ using simultaneous MAAP and multiple-wavelength integrating nephelometer data. $C$ was obtained through Eq. (5) from the AE33 attenuation coefficient, extrapolated at $637 \mathrm{~nm}$ using the absorption Ångström exponent (AAE) from AE33 and the MAAP absorption coefficients at $637 \mathrm{~nm}$. The analysis was performed by binning the SSA data using Freedman and Diaconis (1981) criteria and then averaging the obtained $C$ values within each SSA bin. Binned data were then fitted following Eq. (9) to obtain the experimental values of both $C_{\mathrm{f}}$ and $m_{\mathrm{s}}$.

Figure 1 and Table 1 show the results of the fit for $\mathrm{BCN}$, MSY and MSA for both M8020 and M8060 filter tapes. Moreover, Table 1 compares the $C$ values obtained here with those reported in the literature for the M8020 filter tape. For M8020, we calculated a constant $C_{\mathrm{f}}$ of $2.21 \pm 0.01$ and a cross-sensitivity to scattering, $m_{\mathrm{s}}$, of $1.8 \pm 0.1$ at MSY and of $1.96 \pm 0.02 \%$ and $3.4 \pm 0.1 \%$ at MSA. For the M8060 filter tape, the fit yielded a multiple-scattering constant $C_{\mathrm{f}}$ of $2.50 \pm 0.02$ and a cross-sensitivity to scattering of $1.6 \pm 0.3 \%$ at BCN, a $C_{\mathrm{f}}$ of $1.96 \pm 0.01$ and a $m_{\mathrm{s}}$ of $3.0 \pm 0.1 \%$ at MSY, and a constant $C_{\mathrm{f}}$ of $1.82 \pm 0.02$ and a $m_{\mathrm{s}}$ of $4.9 \pm 0.1 \%$ at MSA.

As a consequence of the cross-sensitivity to scattering, we can appreciate in Fig. 1 a clear increase in $C$ with increasing SSA with an up-to-3-fold increase in $C$ for SSA $>0.90$ 0.95 depending on the station and filter tape considered. The cross-sensitivity to scattering was evident for both filter tapes at the regional (MSY) and mountain (MSA) stations where the probability of measuring SSA higher than $0.90-0.95$ was high $(57 \%-70 \%$ of the data in Fig. 1). Conversely, at the urban site $(\mathrm{BCN})$, where the SSA was on average lower ( $12 \%$ of SSA data were above 0.90 ), a lower cross-sensitivity to scattering was observed. This significant increase in the $C$ factor at high SSA, if not accounted for, can lead to a large overestimation of both $\mathrm{eBC}$ concentrations and absorption coefficients from Aethalometer instruments. This effect can have a larger impact at sites where high SSA values are typically observed such as remote Arctic sites and mountaintop 
(a)

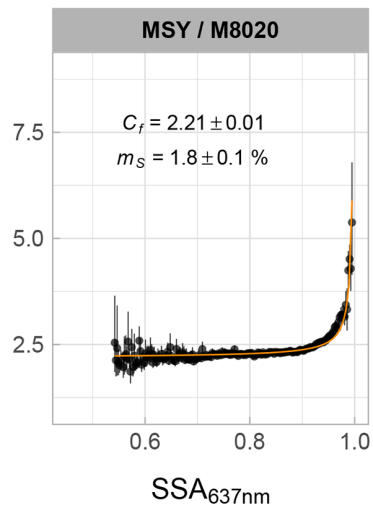

(c)

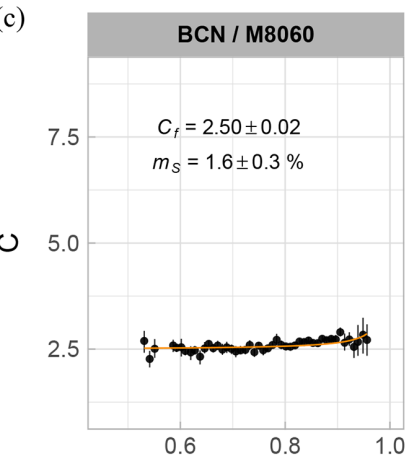

(d)

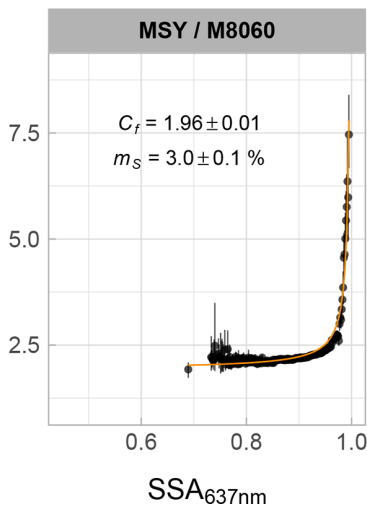

(b)

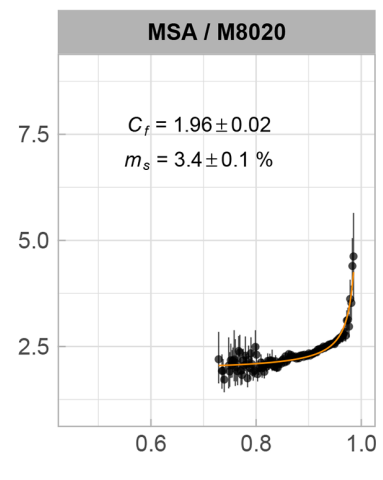

(e)

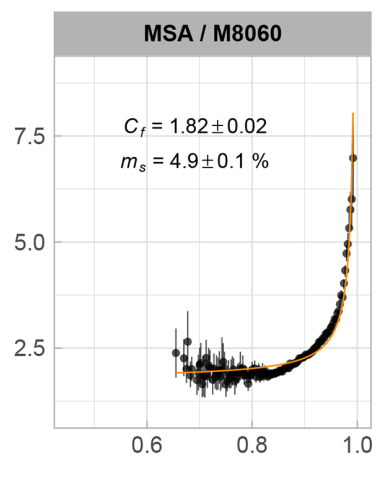

Figure 1. Cross-sensitivity to scattering analysis for TFE-coated glass tape (also known as M8020; a, b) and M8060 filter tape (c-e) for the BCN (c), MSY (a, d) and MSA (b, e) stations obtained by attenuation coefficients from the AE33, absorption coefficients from the MAAP and scattering coefficients from the integrating nephelometer. Each data point represents the mean and the vertical bars the first and third quartile for each bin. The multiple-scattering constant, $C_{\mathrm{f}}$, and cross-sensitivity to scattering, $m_{\mathrm{s}}$, are determined by fitting Eq. (9) to the binned data.

Table 1. AE33 multiple-scattering parameter $C$ for some measurement stations (including BCN, MSY and MSA, in italics) and crosssensitivity to scattering for the BCN, MSY and MSA stations compared to literature values for AE33 TFE-coated glass (M8020). Different approaches, as mentioned in Sect. 3.2, have been used to obtain the factor $C$. Since the literature values are obtained through either one of the methods, we include these values in their corresponding column $\left(C\right.$ or $\left.C_{\text {Deming }}\right)$.

\begin{tabular}{|c|c|c|c|c|c|c|c|}
\hline Site & Characteristics & Filter type & Reference & $C$ & $C_{\text {Deming }}$ & $C_{\mathrm{f}}$ & $m_{\mathrm{S}}(\%)$ \\
\hline \multirow[t]{2}{*}{ Barcelona } & \multirow[t]{2}{*}{ Urban background } & M8020 & This study & $2.29 \pm 0.49$ & $1.99 \pm 0.02$ & - & - \\
\hline & & M8060 & This study & $2.44 \pm 0.57$ & $2.20 \pm 0.02$ & $2.50 \pm 0.02$ & $1.6 \pm 0.3$ \\
\hline \multirow[t]{2}{*}{ Leipzig } & \multirow[t]{2}{*}{ Urban background } & M8020 & Müller (2015) & 3.2 & & & \\
\hline & & M8020 & Bernardoni et al. (2020) & & 2.78 & & \\
\hline Rome & Urban background & M8060 & Valentini et al. (2020a) & 2.66 & & & \\
\hline Klagenfurt & Urban background & M8020 & Drinovec et al. (2020) & 1.57 & & & \\
\hline \multirow[t]{2}{*}{ Montseny } & \multirow[t]{2}{*}{ Regional background } & M8020 & This study & $2.29 \pm 0.46$ & $2.05 \pm 0.02$ & $2.21 \pm 0.01$ & $1.8 \pm 0.1$ \\
\hline & & M8060 & This study & $2.23 \pm 0.30$ & $2.13 \pm 0.01$ & $1.96 \pm 0.01$ & $3.0 \pm 0.1$ \\
\hline \multirow[t]{2}{*}{ Montsec d'Ares } & \multirow[t]{2}{*}{ Mountaintop } & M8020 & This study & $2.36 \pm 0.59$ & $2.21 \pm 0.03$ & $1.96 \pm 0.02$ & $3.4 \pm 0.1$ \\
\hline & & M8060 & This study & $2.51 \pm 0.71$ & $2.05 \pm 0.02$ & $1.82 \pm 0.02$ & $4.9 \pm 0.1$ \\
\hline Mt Bachelor & Mountaintop & M8020 & Laing et al. (2020) & 4.24 & & & \\
\hline
\end{tabular}


sites (Collaud Coen et al., 2004; Gyawali et al., 2009; Andrews et al., 2011; Pandolfi et al., 2014a, 2018; Schmeisser et al., 2018; Ferrero et al., 2019; Laj et al., 2020), as well as in places where increasing or decreasing trends of SSA have been observed (Collaud Coen et al., 2020). This crosssensitivity to scattering of the filter explains the higher $C$ factors obtained on average at these types of sites (Table 1) and suggests the need to use either a site-specific $C$ value or a $C$ value that takes into account the SSA measured by an independent absorption method. Given its impact on the absorption coefficient, this effect needs to be taken into account for climate studies.

In order to further characterize the observed crosssensitivity to scattering, we explored how the variations in $C$ with SSA depended on different intensive aerosol particle optical properties, namely the AAE (Fig. S3), backscatter fraction (BF, Fig. S4) and single-scattering albedo Ångström exponent (SSAAE, Fig. S5). We found that large $C$ values and high SSA were often obtained when the sampled aerosol composition was dominated by mineral dust during Saharan dust outbreaks, as demonstrated by the occurrence of negative SSAAEs at high SSA (Fig. S5). In fact, Saharan dust outbreaks, which are common in the WMB (Escudero et al., 2005; Querol et al., 2004, 2009b, a, 2019; Ealo et al., 2016; Yus-Díez et al., 2020), have the potential to increase the SSA above the average values especially at the regional (MSY) and remote (MSA) stations (e.g. Pandolfi et al., 2014a). In prior studies, negative values of the SSAAE have been associated with an aerosol mixture dominated by mineral dust (Collaud Coen et al., 2004; Ealo et al., 2016; Yus-Díez et al., 2020). Moreover, we observed that high $C$ values (for SSA > 0.95) were also associated with AAE values higher than around 1.5 (see Fig. S3), thus indicating a relatively higher absorption efficiency of the collected particles in the UV, consistent with the presence of either dust or brown carbon (BrC) particles (Kirchstetter et al., 2004a; Chen and Bond, 2010; Zotter et al., 2017; Forello et al., 2019, 2020). Furthermore, low BF values, indicative of the predominance of large particles, were also on average associated with high SSA values (see Fig. S4). Note that the dependence of $C$ vs. SSA on the aforementioned intensive optical properties was not clearly observed in $\mathrm{BCN}$, where, at least for the period under study, local pollution masked the effects of coarse dust particles on the measured intensive optical properties and on SSA which kept values lower than around $0.90-0.95$. The observed dependency of $C$ on intensive aerosol particle optical properties demonstrated that both particle size distribution and chemical composition can affect the reported $C$-vs.-SSA relationships.

\subsection{Multiple-scattering correction factor - average values and seasonal variation}

Here we present the average values and the seasonal cycle of the $C$ factor calculated at $637 \mathrm{~nm}$ at $\mathrm{BCN}$, MSY and MSA.

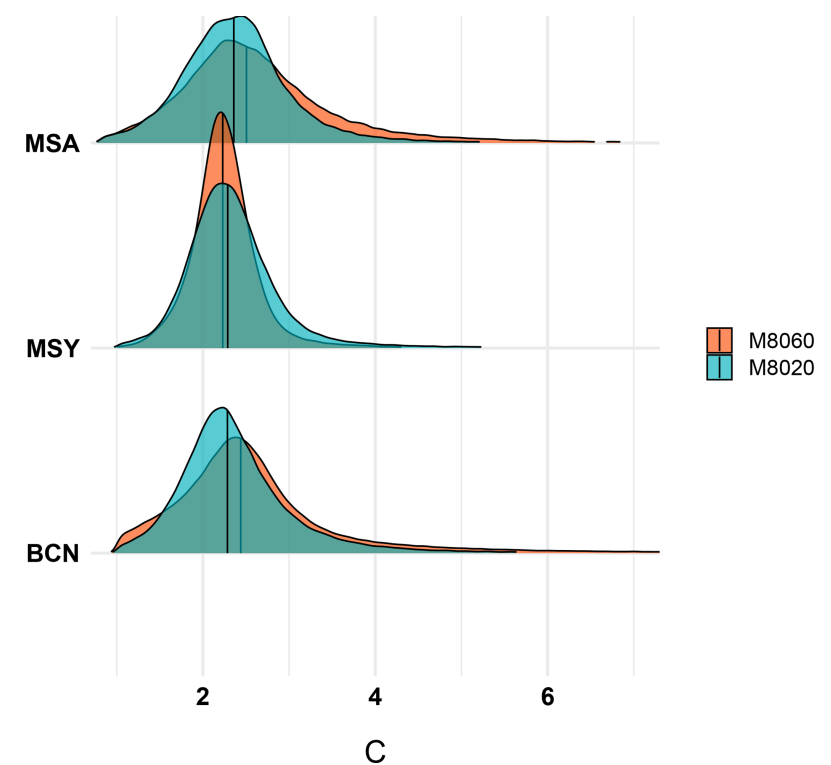

Figure 2. Density distribution of the $C$ factor for each filter type, M8020 and M8060, as obtained through Eq. (5) using both the attenuation coefficient from the AE33 and the absorption coefficient from the MAAP. The vertical line represents the median value of each distribution.

We analysed the multiple-scattering parameter $C$ values both through a Deming regression, taking into account the measurement error in the MAAP (12\%; Petzold and Schönlinner, 2004) and in the AE33 (15\%; Zanatta et al., 2016; Rigler et al., 2020), and by calculating the median value of the $C$ factor density distribution. The uncertainties in the $C$ factor were derived as either the methodological error from the regression slope of the Deming fit or the half width at half maximum (HWHM) of the density distribution of the $C$ factor. We present here the results from both the aforementioned methods because both methods have been reported in the literature (e.g. Backman et al., 2017; Bernardoni et al., 2020; see Table 1 in this work).

The density distribution of the $C$ factor obtained from the ratio (with a variable time resolution, as mentioned in Sect. 2.3.1), showed a quasi-Gaussian distribution at the three measurement sites with a small tail towards higher $C$ values (Fig. 2).

The median values of the $C$ factor for the M8020 filter tape were $2.29 \pm 0.48,2.29 \pm 0.46$ and $2.36 \pm 0.59$ for BCN, MSY and MSA, respectively. These values were on average similar or slightly lower (with differences less than $7 \%$ ) compared to the median $C$ values obtained for the M8060 filter tape of $2.44 \pm 0.57,2.23 \pm 0.30$ and $2.51 \pm 0.71$ (see Table 1). The Deming regression fit results (Fig. S6) showed $C$ values of $1.99 \pm 0.02,2.05 \pm 0.02$ and $2.21 \pm 0.03$ (at $\mathrm{BCN}$, MSY and MSA, respectively) for M8020 which were slightly lower (with differences $<10 \%$ ) compared to the $C$ values of $2.20 \pm 0.02,2.13 \pm 0.01$ and $2.05 \pm 0.02$ obtained for M8060. 

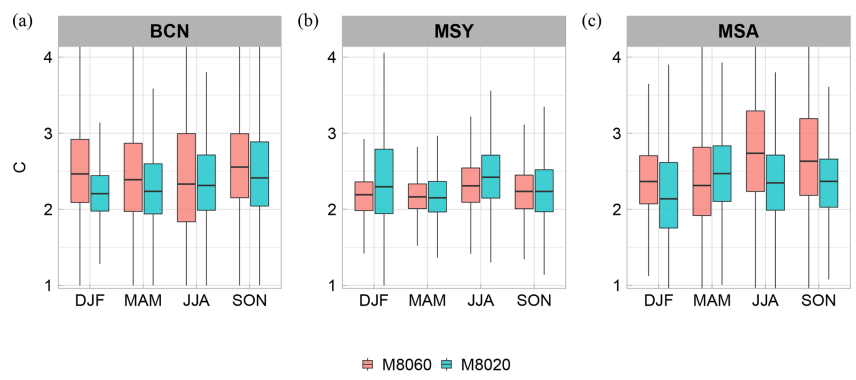

Figure 3. Seasonal evolution of the $C$ factor at the (a) BCN, (b) MSY and (c) MSA measurement stations for both TFE-coated glass (M8020) and M8060 filter tapes. The box plot boxes show the range between the first and third quartile (IQR) with the median value for each season distribution represented by the inner line; the maximum whisker length is proportional to 1.5 times the third and first quartile difference, or inter-quartile range (1.5 $\cdot \mathrm{IQR})$.

Note that the uncertainties from the Deming regression were lower compared to the uncertainties derived as the HWHM of the distributions because the Deming regressions were performed using binned data (see Fig. S6). This also was the likely explanation for the lower $C$ values on average obtained with the Deming regression compared to the median values of the density distribution. The difference in the $C$ values between both methods ranged between $4 \%-18 \%$ depending on the filter tape/measurement station considered (see Table 1). However, both methods were consistent and provided a higher $C$ factor for the M8060 than for the M8020 filter tape.

As reported in Table 1, overall, higher $C$ values were found at MSA, where both the SSA and the cross-sensitivity of the filter tape to scattering were higher compared to at MSY and BCN (see Figs. 1 and S7). The $C$ values for the AE33 M8020 and M8060 filter tapes obtained at urban background stations in Rome (Valentini et al., 2020a) and Leipzig (Müller, 2015; Bernardoni et al., 2020) were in the same range as those found in this work for BCN (Table 1).

Figure 3 shows the seasonal variability in the $C$ factor for the TFE-coated glass and M8060 filter tapes at the three stations. The large variability in the obtained $C$ parameters (see Fig. 3) at the three sites during all the seasons, consistent with the width of the $C$-factor density distribution (Fig. 2) and the SSA seasonal evolution variability (Fig. S7) can be appreciated.

On average, an increase in $C$ was observed at MSY and MSA in summer (JJA) for both filter tapes. This increase was likely driven by a greater influence of diurnal processes and the impact of the atmospheric boundary layer (ABL) during the warm months at these two elevated stations and by changes in the chemical and physical properties of collected particles in summer compared to in winter (DJF). In fact, spring and summer seasons in the WMB are characterized by a high frequency of Saharan dust outbreaks (e.g. Pey et al., 2013; Yus-Díez et al., 2020) and the formation of high concentrations of secondary organic aerosols and secondary sulfate particles (e.g. Ripoll et al., 2015) which in turn increase the particle scattering efficiency and the SSA in summer compared to in winter (Pandolfi et al., 2011). Although dust particles can absorb radiation (e.g. Sokolik and Toon, 1999; Di Biagio et al., 2019), the effect of Saharan dust outbreaks at the measurement stations considered here was to increase the SSA (at $637 \mathrm{~nm}$ ) over the average values. In fact, as shown by Pandolfi et al. (2014a), both scattering and absorption increased at MSY and MSA during Saharan dust outbreaks, but the resulting SSA was higher compared to other atmospheric scenarios typical of the area under study. Therefore, the higher $C$ values observed during Saharan dust outbreaks were coherent with an increase in SSA over the threshold above which $C$ sharply increased (see Figs. 1 and S3-S5). An increase in $C$ when dust particles are deposited on the filter tape was also reported by Di Biagio et al. (2017) for the AE31 Aethalometer. Di Biagio et al. (2017) reported $C$ values for dust particles by generating particles by mechanical shaking of dust samples from different desert soils using AE31 and MAAP measurements, and they reported $C$ values of between 3.6 and 3.96 for Saharan soils (Table 2 of Di Biagio et al., 2017).

As shown in Sect. 3.1, high SSA increased the $C$ values, and, consequently, the $C$ seasonality was affected, to some degree, by the SSA seasonality. In fact, Fig. S7 shows that the seasonal evolution of the SSA at MSY and MSA mirrored quite well the seasonal evolution of $C$, with an increase in both $C$ and SSA towards the warm season. In BCN, the interseason variability in both $C$ and SSA was less pronounced and $C$ remained fairly constant during the different seasons. An exception was in the winter period (DJF) when both $C$ (M8060) and SSA showed minima. Nevertheless, the variability within each season was the largest in $\mathrm{BCN}$, due to a higher variability in the SSA values at this station within each season compared to in MSY and MSA (Fig. S7). The relationship between $C$ and SSA can be also observed in Fig. S8, where the diel cycles of both $C$ and SSA were reported. In BCN, both $C$ and SSA showed two relative minima in the morning and in the afternoon, mirroring the traffic rush hours. At MSY, the sea-breeze-driven transport of pollutants in the afternoon caused a reduction in both SSA and $C$. Conversely, at MSA both $C$ and SSA showed less variability in the diel cycles and less similarity was observed. Note that the similarities commented on above between the diel/seasonal cycles of $C$ and SSA were more or less evident depending on the season/station considered. In fact, we have shown in Fig. 1 that high SSA ( $>0.90-0.95)$ can strongly affect the $C$ values, but less dependency between $C$ and SSA was observed for lower SSA, thus also contributing to masking the similarities between $C$ and SSA reported in Figs. 3, S7 and S8, which were obtained averaging all available data, including $C$ values at lower SSA. 


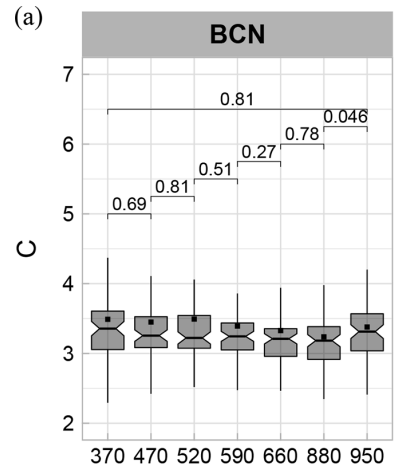

(b)

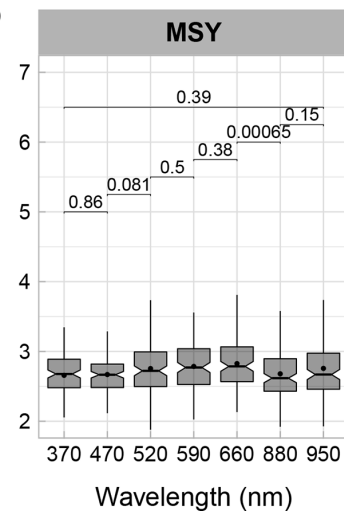

(c)

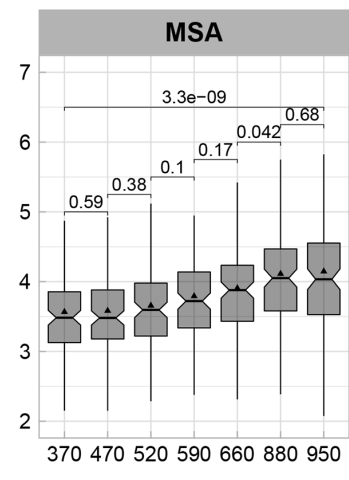

Figure 4. Wavelength dependence of $C$ at BCN, MSY and MSA comparing $b_{\text {atn }}$ from the AE33 measured at each wavelength and $b_{\text {abs }}$ interpolated and extrapolated to the same wavelength from PP_UniMI. Box plots have been obtained as in Fig. 3 with the addition of the mean value of the distribution for each wavelength represented by a marker. The values above the box plots between adjacent wavelengths and between 370 and $950 \mathrm{~nm}$ wavelength box plots show the obtained $p$ values, with $p<0.05$ meaning a statistically significant difference.

\subsection{Wavelength dependence analysis from the PP_UniMI-vs.-AE33 comparison}

The spectral dependence of the AE33 $C$ factor, $C(\lambda)$, was studied at the three stations by comparing the attenuation coefficients, $b_{\text {atn }}$, from AE33 at seven different wavelengths with the absorption coefficients, $b_{\text {abs }}$, from PP_UniMI. To this aim, the PP_UniMI absorption coefficients were interpolated and extrapolated to the seven AE33 wavelengths using the absorption Ångström exponent (AAE) obtained from the original PP_UniMI measurements. The obtained mean AAE were $1.12 \pm 0.17,1.29 \pm 0.24$ and $1.35 \pm 0.18$ for the $\mathrm{BCN}$, MSY and MSA stations, respectively, with an increase from the urban (BCN) to the regional (MSY) and remote (MSA) sites due to the increase in the relative importance of nonfossil BC sources (e.g. biomass burning) and Saharan dust at the remote sites compared to $\mathrm{BCN}$.

Figure 4 shows that at the urban $(\mathrm{BCN})$ and regional (MSY) stations the $C$ factor did not present a statistically significant dependence on the wavelength. However, Fig. $4 \mathrm{c}$ shows that at the remote MSA station the multiplescattering parameter $C$ presented a statistically significant increase between $370 \mathrm{~nm}(C=3.47)$ and $950 \mathrm{~nm}(C=$ 4.03) (see Table S2). The observed increase in the $C$ factor with wavelength affects the absorption coefficients derived from the AE33 attenuation measurements and, consequently, can affect all the intensive optical parameters such as the AAE, SSA and SSAAE which can be derived from the multi-wavelength AE33 absorption measurements and scattering coefficient measurements. Moreover, a wavelength-dependent $C$ factor can impair Aethalometerbased BC source apportionment analysis, such as that of the Aethalometer model, used to determine the contribution from fossil fuels vs. biomass burning emissions (Sandradewi et al., 2008). Contradictory results have been reported in the literature about the spectral dependence of $C$ for older versions of the Aethalometer (model AE31). For example, Weingartner et al. (2003) found a strong indication of the independence of $C$ from the wavelength, and Segura et al. (2014) did not find any wavelength dependence of the multiple-scattering parameter $C$. Conversely, Bernardoni et al. (2020) observed a decrease in the $C$ factor with wavelengths, although it was not statistically significant.

As can be appreciated by comparing Figs. 2-4, the multiple-scattering correction factors obtained using the PP_UniMI reference instrument were larger than those obtained with the MAAP as a consequence of the offset in the absorption measurements between the MAAP and PP_UniMI. A detailed discussion of this offset can be found in Fig. A1 and in Fig. 2 in Valentini et al. (2020b).

Hereafter, we propose a possible explanation for the different spectral dependencies found for $C$ at the measurement sites considered here. We have shown in Sect. 3.1 that, independently from the measurement station considered, the cross-sensitivity to scattering can strongly increase $C$ for SSA values above an upper threshold. To explore if the SSA can also affect the $C$ wavelength dependence, we studied the wavelength dependence of $C$ for SSA values above and below the site-dependent SSA thresholds. Figure 5 shows the comparison between the $C$ factor at MSY and MSA for SSA above (high SSA) and below (low SSA) the SSA thresholds of 0.95 and 0.9 , respectively, for MSY and MSA (see Fig. 1). Figure 5 shows that at MSA there was a statistically significant increase in $C$ with the wavelength for SSA $>0.90$, whereas no statistically significant increase was observed for SSA $<0.90$. For this specific analysis, based on the PP_UniMI off-line measurements, $86 \%$ of SSA values at MSA (68 samples out of 79) were above the SSA threshold of 0.95 . At MSY, only 1 sample out of 126 was characterized by an SSA value higher than the SSA threshold of 0.95 , thus preventing a robust statistical analysis of the $C$ wavelength dependence for high SSA at MSY. Despite this, a $17 \%$ in- 

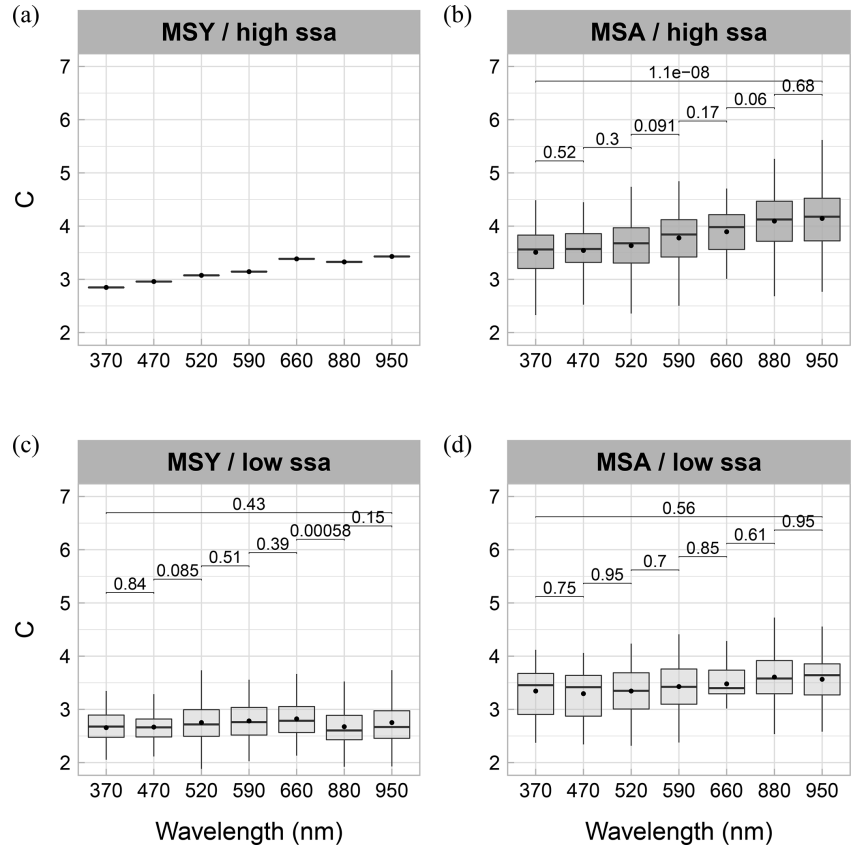

Figure 5. Wavelength dependence of $C$ at MSY (a, c) and MSA (b, d) obtained comparing $b_{\text {atn }}$ from the AE33 measured at each wavelength and $b_{\text {abs }}$ interpolated and extrapolated to the same wavelength from PP_UniMI. Box plots have been obtained as in Fig. 3 and separated into two categories depending on whether the SSA was above ("high ssa"; $\mathbf{a}, \mathbf{b}$ ) or below ("low ssa"; c, d) the threshold at which $C$ sharply increases. As in Fig. 3, the values above the box plots between adjacent wavelengths and between 370 and $950 \mathrm{~nm}$ wavelength box plots show the obtained $p$ values, with $p<0.05$ meaning a statistically significant difference.

crease in $C$ with the wavelength, from 2.85 at $370 \mathrm{~nm}$ to 3.43 at $950 \mathrm{~nm}$, for this single point was observed (see Fig. 5a). At MSY, similarly to MSA, $C$ did not show any dependence on the wavelength for SSA $<0.95$ (see Fig. 5c). Thus, this analysis demonstrated that a high SSA of the particles deposited on the filter tape can increase the $C$ values, influencing at the same time their wavelength dependence.

We have shown in Sect. 3.1 that the sharp increase in $C$ at high SSA at the stations herein analysed can be associated with the presence of particles dominated by dust, characterized by low SSAAEs and BFs and high AAEs and SSA (Figs. S3-S5). Therefore, we performed a similar $C$ spectral dependence analysis to that in Fig. 5 but separating the days affected by Saharan dust (dust) from the days without dust influence (no-dust). As shown in Fig. 6, no spectral dependence of $C$ was observed during either dust or no-dust scenarios at MSY. This lack of dependence on the dust intrusions could be due to the limited number of off-line samples at MSY characterized by high SSA (1 out of 126). Thus, due to the low temporal resolution of off-line PP_UniMI measurements, even during Saharan dust days the SSA at MSY rarely increased above the SSA threshold. Nevertheless, us-
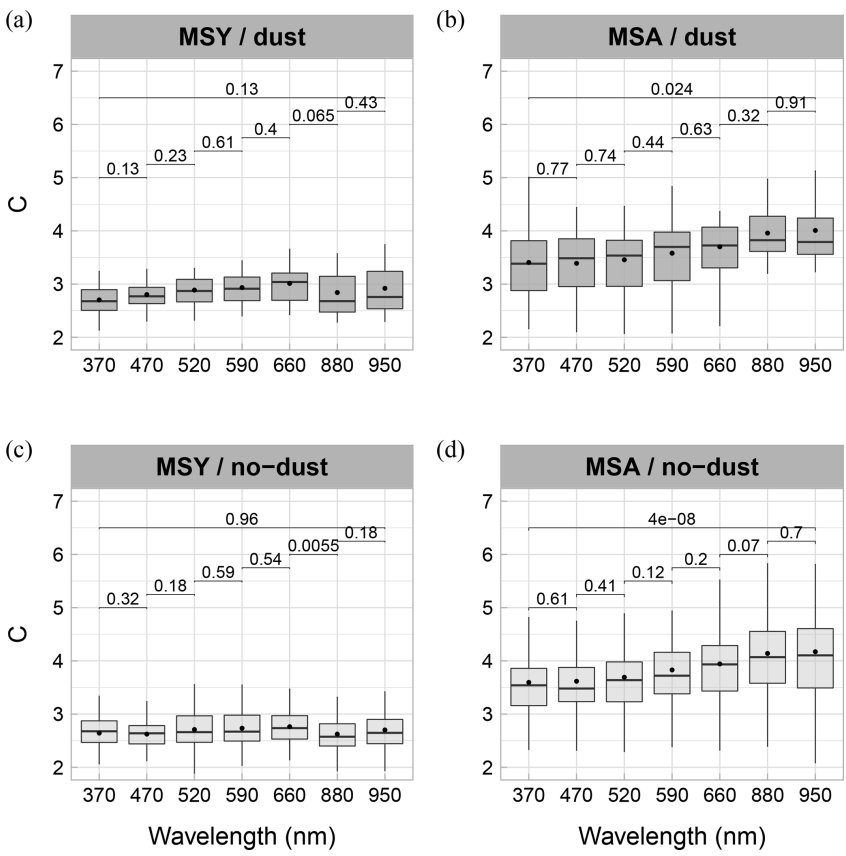

Figure 6. Wavelength dependence of $C$ at MSY (a, c) and MSA (b, d) obtained comparing $b_{\text {atn }}$ from the AE33 measured at each wavelength and $b_{\mathrm{abs}}$ interpolated and extrapolated to the same wavelength from PP_UniMI. Box plots have been obtained as in Fig. 3 and separated into two categories depending on whether Saharan dust outbreaks took place (dust) or not (no-dust). As in Fig. 3, the values above the box plots between adjacent wavelengths and between 370 and $950 \mathrm{~nm}$ wavelength box plots show the obtained $p$ values, with $p<0.05$ meaning a statistically significant difference.

ing high-time-resolution data (see Fig. 1) the potential effect of dust particles to increase the SSA (and consequently $C$ ) was evident at both MSY and MSA. At MSA (see Fig. 6) $C$ showed a statistically significant increase with wavelength for both dust and no-dust samples due to the fact that the samples with high SSA at MSA $(86 \%)$ were well distributed between the two scenarios. Thus, these results confirmed that the SSA was the main parameter that influenced the spectral behaviour of the $C$ parameter.

To further explore the possible causes that contributed to the different $C$ spectral dependencies observed, we performed a similar analysis to that in Virkkula et al. (2015) by comparing $C$ and its wavelength dependence with different intensive aerosol particle optical properties, namely the SSA, BF and SSAAE. Virkkula et al. (2015) and Drinovec et al. (2017) have shown that the AE33 factor loading parameter, $k$, increases with an increasing BF (smaller particles) and decreases with increasing SSA and that the wavelength dependence of $k$ also depends on these two optical properties as well as on the particle mixing state. In Fig. S9 in the Supplement we present a similar analysis by studying the effects of these intensive optical properties on the multiple-scattering 
parameter $C$ instead of on $k$. Figure S9 shows the slope of $C$ with the wavelength (i.e. the wavelength dependence of $C$ ) with the SSA, BF and SSAAE at the three sites. No clear relationship was observed between the $C$ slope and the three intensive optical properties at both BCN and MSY. Moreover, the $C$ slopes at these two sites were close to zero for the considered intensive optical properties. The observed lack of a $C$ gradient was again likely due to the fact that at $\mathrm{BCN}$ and MSY the SSA did not exceed the threshold value, even when the SSAAE indicated the possible presence of Saharan dust intrusions at MSY (see Fig. S9h). However, Fig. S9c shows that at MSA there was a shift of the $C$ slope towards large positive values when SSA was above 0.95. Below this SSA threshold value, the $C$ slope was close to zero, confirming the reduced $C$ wavelength dependence for low SSA values at MSA. Moreover, when the SSAAE (BF) at MSA (see Fig. S9i and f) decreased towards negative (low) values (Saharan dust intrusions), the slope of $C$ increased, again confirming the potential of coarse Saharan dust to increase the SSA and, consequently, $C$ especially at the remote site. Note that, as already commented on (see Fig. 6), the $C$ slope also kept positive values at MSA for the samples not dominated by dust (SSAAE $>0$ ), thus further indicating the predominance effect of SSA on the $C$ wavelength dependence. Thus, the results presented in Fig. S9 confirm the effects of SSA on $C$ presented in Figs. 5 and 6.

The lack of points for BCN (none) and MSY (1 of 126) for large SSA values, especially above the SSA threshold obtained in Fig. 1, prevented extrapolating the results to other measurement background conditions, and further studies should be performed to better characterize the spectral behaviour of $C$ and its dependency on the cross-sensitivity to scattering under different atmospheric conditions/scenarios. This is especially important, as already commented on, in view of the contradictory results reported in the literature (e.g. Weingartner et al., 2003; Segura et al., 2014; Bernardoni et al., 2020). The results presented here clearly indicated that when the SSA exceeded a given site-dependent threshold, as determined using the method in Sect. 3.1, the $C$ values and their wavelength dependence increased. For the measurement sites considered here, Saharan dust outbreaks were identified as a possible cause for SSA values higher than the threshold. However, from a general point of view, other factors, including the location of the measurement stations and/or absence of anthropogenic pollution, can determine the presence of a particle mixture with high or very high SSA.

Finally, we performed a sensitivity study on the effects that using a wavelength-dependent $C(C(\lambda))$ had on the AAE derived from AE33 measurements, comparing the results with those obtained using the usual approach based on the application of a constant $C$ factor ( $C$ (const)). Figure 7 shows that the AAE values for BCN and MSY did not present any significant variation (see Table S4), with AAE mean values of $1.19 \pm 0.15$ and $1.27 \pm 0.12$ (at BCN and MSY,

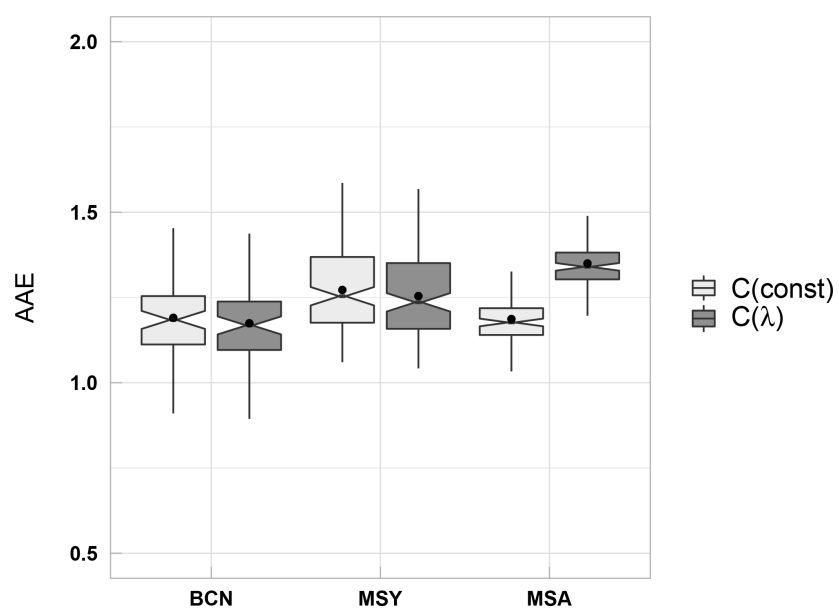

Figure 7. The absorption Ångström exponent (AAE) calculated with a constant $C$ (const) and the wavelength-dependent $C(\lambda)$ for all stations. Box plots have been obtained as in Figs. 3 and 4, with the markers indicating the mean AAE values.

respectively) for $C$ (const) and $1.17 \pm 0.15$ and $1.25 \pm 0.12$ (for BCN and MSY, respectively) for $C(\lambda)$. These results for BCN and MSY were coherent with the observed lack of spectral dependence of $C$ at these two stations (Fig. 4). However, at MSA the observed increase in $C$ with the wavelength introduced an increase into the AAE of around $13 \%$, from $1.19 \pm 0.07(C$ (const) $)$ to $1.35 \pm 0.07(C(\lambda))$. Similarly, Fig. S10a and b present the results of a sensitivity analysis performed to understand the effects that using a constant or a wavelength-dependent $C$ had on the SSA at 470, 660 and $950 \mathrm{~nm}$. As with the AAE, Fig. S10c shows no significant variation in SSA at the three considered wavelengths at $\mathrm{BCN}$ and MSY, again consistent with the observed lack of dependence of the $C$ factor on the wavelength at these two sites. However, Fig. S10 shows a statistically significant increase in the SSA at the MSA station of around $1.3 \%$ at $660 \mathrm{~nm}$ and $2 \%$ at $950 \mathrm{~nm}$ when using $C(\lambda)$ instead of $C$ (const). Conversely, as expected, no statistically significant change was appreciated at the lower wavelength, $470 \mathrm{~nm}$. This variation introduced by $C(\lambda)$ into the AAE and SSA, although not large, is relevant since it occurs at the threshold of the SSA value for which a substantial increase in $C$ as a function of SSA is observed, as shown in Sect. 3.1.

\section{Conclusions}

In this work we studied the multiple-scattering parameter $C$ for two filter tapes used in AE33 dual-spot Aethalometers, i.e. the previously used M8020 and the currently used M8060 filter tapes. For this, we used data collected at three different background stations in NE Spain: an urban background station in Barcelona, $\mathrm{BCN}$; a regional background station at Montseny, MSY; and a mountaintop station at Montsec 
d'Ares, MSA. We obtained the $C$ correction factor comparing the AE33 attenuation measurements with the absorption coefficients measured from MAAP instruments and used simultaneous scattering measurements from an integrating nephelometer to characterize the cross-sensitivity to scattering of $C$. Moreover, we studied the $C$ wavelength dependence at the three sites comparing the AE33 attenuation coefficients with the absorption coefficients from the off-line multi-wavelength PP_UniMI.

We presented here a novel approach to characterize the cross-sensitivity to scattering of the $C$ correction factor. This approach consisted in fitting the measurements of $C$ versus SSA. The fits provided the constant $C_{\mathrm{f}}$ and a cross-sensitivity factor $m_{\mathrm{S}}$. We applied the fits to the M8020 filter tape at MSY and MSA, and we obtained higher cross-sensitivity values of the $C$ factor $(1.8 \pm 0.1 \%$ and $3.4 \pm 0.1 \%$ at MSY and MSA, respectively) compared to those reported in the literature (around $1 \%-1.5 \%$ ). For the first time, we also characterized here the cross-sensitivity to scattering of the new M8060 filter tape. We obtained a higher cross-sensitivity to scattering for the M8060 than for the M8020 filter tape, with values of $1.6 \pm 0.3 \%, 3.0 \pm 0.1 \%$ and $4.9 \pm 0.1 \%$ for $\mathrm{BCN}$, MSY and MSA, respectively. The multiple-scattering parameter, $C_{\mathrm{f}}$, for the M8020 filter tape was $2.21 \pm 0.01$ at MSY and $1.96 \pm 0.02$ at MSA. For the M8060 filter tape the fit led to $C_{\mathrm{f}}$ values of $2.50 \pm 0.02$ at $\mathrm{BCN}, 1.96 \pm 0.01$ at $\mathrm{MSY}$ and $1.82 \pm 0.02$ at MSA. The consequence of this crosssensitivity to scattering resulted in a large increase in the $C$ values, up to a 3-fold increase, for SSA values above 0.90.95 . This significant increase in the $C$ factor at high SSA, if not accounted for, can lead to a large overestimation of both eBC concentrations and absorption coefficients measured by Aethalometers. This can be especially relevant at sites typically characterized by an aerosol mixture with high SSA. In fact, the effect of this cross-sensitivity to scattering of $C$ was the likely reason explaining the higher $C$ values reported in the literature for mountaintop and Arctic measurement stations. Here, we observed larger $C$ values and higher crosssensitivity to scattering at the mountain station and much less $C$ variability at the urban site, where the SSA rarely exceeded the SSA threshold from which changes in $C$ can be observed.

Overall, the main difference between the two filter tapes studied here was the higher cross-sensitivity to scattering observed for the currently used M8060 filter tape compared to the previously used M8020 filter tape. Despite the different cross-sensitivity to scattering, both filter tapes showed average $C$ values which fall within the measurement uncertainties.

We found an average multiple-scattering parameter $C$ at $637 \mathrm{~nm}$ of 2.29, 2.29 and 2.36 for the M8020 filter tape and of 2.44, 2.23 and 2.51 for the M8060 filter tape for the BCN, MSY and MSA measurement stations, respectively. Due to the dominant effect of SSA on $C$, the obtained $C$ factors showed seasonal and diel variability at the three sites that mirrored the variability in SSA. At MSY and MSA higher $C$ values were on average observed in summer due to changes in the physical-chemical aerosol properties that led to SSA values being on average higher in summer than in winter. A larger fraction of dust particles and formation of secondary organic aerosols and secondary sulfates likely explained the observed increase in $C$ in summer at these regional/remote sites. However, at the urban background station of BCN the $C$ values remain fairly constant throughout the year.

We also analysed the wavelength dependence of the $C$ parameter for the M8060 filter tape at BCN, MSY and MSA by comparing the AE33 attenuation data with the off-line PP_UniMI absorption measurements performed on selected MAAP spots. Overall, we found a statistically significant increase with the wavelength, from 3.47 for $370 \mathrm{~nm}$ to 4.03 for $950 \mathrm{~nm}$ at the mountaintop station (MSA), whereas at the BCN and MSY background stations no statistically significant dependence was found. The reason for the lack of wavelength dependence of $C$ at BCN and MSY was the lack of MAAP spots characterized by high SSA. Thus, due to the low temporal resolution of off-line PP_UniMI measurements, the SSA at MSY and, especially, at BCN rarely increased above the SSA threshold. Conversely, the wavelength dependence of $C$ at the mountain station was due to the high probability of measuring SSA values higher than the site-dependent SSA threshold, from which the $C$ values start to increase. For this analysis, we studied the $C$ wavelength dependence separately for samples characterized by high SSA (higher than the site-dependent threshold) and low SSA and observed that at MSA no dependence of $C$ on the wavelength was observed for samples with low SSA, whereas a clear dependence was observed for the sample with high SSA. Thus, the analysis presented here demonstrated that a high SSA of the particles deposited on the filter tape can increase the $C$ values, influencing at the same time their wavelength dependence. Interestingly, only $1 \mathrm{sam}$ ple (out of 126) collected at the MSY regional station was characterized by high SSA, and for this sample the calculated $C$ strongly increased with wavelength. The results presented here clearly indicated that when the SSA exceeded a given site-dependent threshold, the $C$ values and their wavelength dependence increased. For the measurement sites considered here, Saharan dust outbreaks were identified as a possible cause for SSA values higher than the threshold. However, other factors, including the location of the measurement stations and/or the absence of anthropogenic pollution, can determine the presence of a particle mixture with high or very high SSA. We also investigated the effect of considering a wavelength-dependent $C$ at the MSA station compared to using a constant $C$ for the absorption Ångström exponent (AAE) and the single-scattering albedo (SSA) through sensitivity tests. Results revealed an increase in the AAE by $13 \%$ and an increase in the SSA by $1.3 \%$ when using the wavelength-dependent $C$ factor compared to using a constant $C$ factor (i.e. with no $\lambda$ dependence). This effect may impact any source apportionment method which takes into ac- 
count the multi-wavelength absorption values from the AE33 (e.g. the Aethalometer model).

In summary, based on the results herein presented, the absorption coefficients from AE33 data can be corrected with different degrees of confidence depending on the information available to estimate the multiple-scattering parameter $C$ :

- A tailored dynamic multiple-scattering parameter can be obtained if on-line simultaneous reference absorption measurements are available. In this case, a dynamic $C$ value with a high temporal resolution can be obtained, allowing an in situ correction of AE33 data and allowing the studying of, for example, the diel/seasonal cycles of the multiple-scattering parameter. Here we used on-line MAAP absorption measurements at one wavelength for the determination of a dynamic $C$ value at the same MAAP wavelength.

- If independent reference multi-wavelength absorption measurements are available, then the dependence of the multiple-scattering parameter on wavelengths can be studied. Here we determined the wavelength dependence of the multiple-scattering parameter $C$ by using the polar photometer (PP_UniMI) off-line absorption measurements performed on the MAAP filter spots and by comparing the off-line PP_UniMI measurements with AE33 attenuation data integrated over the MAAP filter spots' timestamp.

- If reference absorption measurements are not available for the experimental determination of $C$, then the average values of the multiple-scattering parameter provided here for three different measurement stations can be used as a reference.

- If both independent reference absorption measurements and scattering measurements are available, then the cross-sensitivity to scattering of the multiple-scattering parameter $C$ can be determined by studying the relationship between $C$ and single-scattering albedo (SSA). In this case, a parameterization can be obtained relating $C$ and SSA.

- If SSA measurements are not available, this work provides parameterized formulas that allow calculating $C$ over a wide range of SSA values.

Finally, the $C$ values obtained in this work for different station types (urban, regional, remote) may serve as a reference for similar background measurement sites where the methodology presented here cannot be applied. Nevertheless, discrepancies may arise due to the possible differences in aerosol sources, composition and mixing state at different sites that, accordingly, will result in different aerosol particle optical properties. Similar analysis performed at other measurement sites with similar features may reduce the uncertainties around the applicability of the results presented here to other stations.



Figure A1. Comparison between the aerosol absorption coefficient measured by PP_UniMI on sample spots $\left(\sigma_{\text {ap_PP_UniMI }}\right)$ and the $\operatorname{MAAP}\left(\sigma_{\text {ap_MAAP }}\right)$.

\section{Appendix A: Absorption coefficient relationship between the MAAP and the PP_UniMI polar photometer for the MSA station}

This appendix aims to show the result of applying the same methodology as in Sect. 3.1 of Valentini et al. (2020b) to the PP_UniMI-analysed dataset for obtaining the bias for the MSA station in the absorption coefficient measurements between the MAAP and the PP_UniMI polar photometer (Fig. A1). It consists in the application of a Deming regression fit, which results in a slope of $0.81 \pm 0.01$ for our dataset.

Code and data availability. The

Montseny (http://ebas.nilu.no/Pages/DataSetList.aspx?key= 562F658B11934EAC92BB0A2F0CD29A40, last access: 20 September 2021; EBAS, 2021b) and Montsec d'Ares (http://ebas.nilu.no/Pages/DataSetList.aspx?key= 4F862F47EC324FD6AAFA5CD8CF6F8EFB, last access: 20 September 2021; EBAS, 2021a) datasets used for this publication are accessible online on the WDCA (World Data Centre for Aerosols) web page: http://ebas.nilu.no (last access: 20 September 2021). The Barcelona datasets were collected within different national and regional projects and/or agreements and are available upon request. The code used for analysis can be obtained upon request to the corresponding author.

Supplement. The supplement related to this article is available online at: https://doi.org/10.5194/amt-14-6335-2021-supplement. 
Author contributions. DC, SV, RV and VB performed and analysed the measurements with the PP_UniMI polar photometer. NP, CR, MP, AA and JYD carried out the maintenance and supervision of the BCN, MSY and MSA supersites. AA, GM, MP and XQ played a crucial role in the processes of shaping the manuscript structure as well as in helping with the data analysis. JYD developed the data process, the analysis of the results, and summarized and expressed them in this paper. All authors provided advice regarding the manuscript structure and content as well as contributed to the writing of the final manuscript.

Competing interests. At the time of the research, Martin Rigler and Matic Ivančič were also employed by the manufacturer of the Aethalometer AE33.

Disclaimer. Publisher's note: Copernicus Publications remains neutral with regard to jurisdictional claims in published maps and institutional affiliations.

Acknowledgements. The authors acknowledge the support from the Spanish Ministry of Economy, Industry and Competitiveness and I+D+I "Retos Colaboración" funds, the Generalitat de Catalunya, and the European Commission. The authors also acknowledge support of the COST Action CA16109 COLOSSAL. Griša Močnik acknowledges support from the Slovenian Research Agency. IDAEACSIC is also acknowledged.

Financial support. This research has been supported by the Ministerio de Economía, Industria y Competitividad, Gobierno de España (CAIAC project (grant no. PID2019-108990PB-100)); the European Cooperation in Science and Technology (Action CA16109 COLOSSAL); the Agència de Gestió d'Ajuts Universitaris i de Recerca (AGAUR 2017 SGR41); and the European Commission, Horizon 2020 Framework Programme (ACTRIS IMP (grant no. 871115)).

Review statement. This paper was edited by Pierre Herckes and reviewed by two anonymous referees.

\section{References}

Ajtai, T., Filep, Á., Schnaiter, M., Linke, C., Vragel, M., Bozóki, Z. Á., Szabó, G., and Leisner, T.: A novel multi-wavelength photoacoustic spectrometer for the measurement of the UV-vis-NIR spectral absorption coefficient of atmospheric aerosols, J. Aerosol Sci., 41, 1020-1029, https://doi.org/10.1016/j.jaerosci.2010.07.008, 2010.

Alfaro, S., Lafon, S., Rajot, J., Formenti, P., Gaudichet, A., and Maille, M.: Iron oxides and light absorption by pure desert dust: An experimental study, J. Geophys. Res., 109, D08208, https://doi.org/10.1029/2003JD004374, 2004.
Amato, F., Querol, X., Alastuey, A., Pandolfi, M., Moreno, T., Gracia, J., and Rodriguez, P.: Evaluating urban $\mathrm{PM}_{10}$ pollution benefit induced by street cleaning activities, Atmos. Environ., 43, 4472-4480, 2009

Andreae, M. O. and Gelencsér, A.: Black carbon or brown carbon? The nature of light-absorbing carbonaceous aerosols, Atmos. Chem. Phys., 6, 3131-3148, https://doi.org/10.5194/acp-63131-2006, 2006.

Andrews, E., Ogren, J. A., Bonasoni, P., Marinoni, A., Cuevas, E., Rodríguez, S., Sun, J. Y., Jaffe, D. A., Fischer, E. V., Baltensperger, U., Weingartner, E., Collaud Coen, M., Sharma, S., Macdonald, A. M., Leaitch, W. R., Lin, N.-H., Laj, P., Arsov, T., Kalapov, I., Jefferson, A., and Sheridan, P.: Climatology of aerosol radiative properties in the free troposphere, Atmos. Res., 102, 365-393, 2011.

Arnott, W. P., Hamasha, K., Moosmüller, H., Sheridan, P. J., and Ogren, J. A.: Towards aerosol light-absorption measurements with a 7-wavelength aethalometer: Evaluation with a photoacoustic instrument and 3-wavelength nephelometer, Aerosol Sci. Tech., 39, 17-29, https://doi.org/10.1080/027868290901972, 2005.

Backman, J., Schmeisser, L., Virkkula, A., Ogren, J. A., Asmi, E., Starkweather, S., Sharma, S., Eleftheriadis, K., Uttal, T., Jefferson, A., Bergin, M., Makshtas, A., Tunved, P., and Fiebig, M.: On Aethalometer measurement uncertainties and an instrument correction factor for the Arctic, Atmos. Meas. Tech., 10, 50395062, https://doi.org/10.5194/amt-10-5039-2017, 2017.

Bergametti, G., Dutot, A.-L., Buat-Menard, P., Losno, R., and Remoudaki, E.: Seasonal variability of the elemental composition of atmospheric aerosol particles over the northwestern Mediterranean, Tellus B, 41, 353-361, 1989.

Bergstrom, R. W., Pilewskie, P., Russell, P. B., Redemann, J., Bond, T. C., Quinn, P. K., and Sierau, B.: Spectral absorption properties of atmospheric aerosols, Atmos. Chem. Phys., 7, 5937-5943, https://doi.org/10.5194/acp-7-5937-2007, 2007.

Bernardoni, V., Valli, G., and Vecchi, R.: Set-up of a multi wavelength polar photometer for off-line absorption coefficient measurements on 1-h resolved aerosol samples, J. Aerosol Sci., 107, 84-93, https://doi.org/10.1016/j.jaerosci.2017.02.009, 2017.

Bernardoni, V., Ferrero, L., Bolzacchini, E., Forello, A. C., Gregorič, A., Massabò, D., Močnik, G., Prati, P., Rigler, M., Santagostini, L., Soldan, F., Valentini, S., Valli, G., and Vecchi, R.: Determination of Aethalometer multiple-scattering enhancement parameters and impact on source apportionment during the winter 2017/18 EMEP/ACTRIS/COLOSSAL campaign in Milan, Atmos. Meas. Tech., 14, 2919-2940, https://doi.org/10.5194/amt-14-2919-2021, 2021.

Bond, T. C., Anderson, T. L., and Campbell, D.: Calibration and Intercomparison of Filter-Based Measurements of Visible Light Absorption by Aerosols, Aerosol Sci. Tech., 30, 582-600, https://doi.org/10.1080/027868299304435, 1999.

Bond, T. C., Doherty, S. J., Fahey, D. W., Forster, P. M. Berntsen, T., DeAngelo, B. J., Flanner, M. G., Ghan, S., Kärcher, B., Koch, D., Kinne, S., Kondo, Y., Quinn, P. K., Sarofim, M. C., Schultz, M. G., Schulz, M., Venkataraman, C., Zhang, H., Zhang, S., Bellouin, N., Guttikunda, S. K., Hopke, P. K., Jacobson, M. Z., Kaiser, J. W., Klimont, Z., Lohmann, U., Schwarz, J. P., Shindell, D., Storelvmo, T., Warren, S. G., and Zender, C. S.: Bound- 
ing the role of black carbon in the climate system: A scientific assessment, J. Geophys. Res.-Atmos., 118, 5380-5552, 2013.

Brean, J., Beddows, D. C. S., Shi, Z., Temime-Roussel, B., Marchand, N., Querol, X., Alastuey, A., Minguillón, M. C., and Harrison, R. M.: Molecular insights into new particle formation in Barcelona, Spain, Atmos. Chem. Phys., 20, 10029-10045, https://doi.org/10.5194/acp-20-10029-2020, 2020.

Cappa, C. D., Zhang, X., Russell, L. M., Collier, S., Lee, A. K., Chen, C. L., Betha, R., Chen, S., Liu, J., Price, D. J., Sanchez, K. J., McMeeking, G. R., Williams, L. R., Onasch, T. B., Worsnop, D. R., Abbatt, J., and Zhang, Q.: Light Absorption by Ambient Black and Brown Carbon and its Dependence on Black Carbon Coating State for Two California, USA, Cities in Winter and Summer, J. Geophys. Res.-Atmos., 124, 1550-1577, https://doi.org/10.1029/2018JD029501, 2019.

Chen, Y. and Bond, T. C.: Light absorption by organic carbon from wood combustion, Atmos. Chem. Phys., 10, 1773-1787, https://doi.org/10.5194/acp-10-1773-2010, 2010.

Collaud Coen, M., Weingartner, E., Schaub, D., Hueglin, C., Corrigan, C., Henning, S., Schwikowski, M., and Baltensperger, U.: Saharan dust events at the Jungfraujoch: detection by wavelength dependence of the single scattering albedo and first climatology analysis, Atmos. Chem. Phys., 4, 2465-2480, https://doi.org/10.5194/acp-4-2465-2004, 2004.

Collaud Coen, M., Weingartner, E., Apituley, A., Ceburnis, D., Fierz-Schmidhauser, R., Flentje, H., Henzing, J. S., Jennings, S. G., Moerman, M., Petzold, A., Schmid, O., and Baltensperger, U.: Minimizing light absorption measurement artifacts of the Aethalometer: evaluation of five correction algorithms, Atmos. Meas. Tech., 3, 457-474, https://doi.org/10.5194/amt-3-4572010, 2010.

Collaud Coen, M., Andrews, E., Alastuey, A., Arsov, T. P., Backman, J., Brem, B. T., Bukowiecki, N., Couret, C., Eleftheriadis, K., Flentje, H., Fiebig, M., Gysel-Beer, M., Hand, J. L., Hoffer, A., Hooda, R., Hueglin, C., Joubert, W., Keywood, M., Kim, J. E., Kim, S.-W., Labuschagne, C., Lin, N.-H., Lin, Y., Lund Myhre, C., Luoma, K., Lyamani, H., Marinoni, A., MayolBracero, O. L., Mihalopoulos, N., Pandolfi, M., Prats, N., Prenni, A. J., Putaud, J.-P., Ries, L., Reisen, F., Sellegri, K., Sharma, S., Sheridan, P., Sherman, J. P., Sun, J., Titos, G., Torres, E., Tuch, T., Weller, R., Wiedensohler, A., Zieger, P., and Laj, P.: Multidecadal trend analysis of in situ aerosol radiative properties around the world, Atmos. Chem. Phys., 20, 8867-8908, https://doi.org/10.5194/acp-20-8867-2020, 2020.

Corbin, J. C., Pieber, S. M., Czech, H., Zanatta, M., Jakobi, G., Massabò, D., Orasche, J., El Haddad, I., Mensah, A. A., Stengel, B., Drinovec, L., Mocnik, G., Zimmermann, R., Prévôt, A. S., and Gysel, M.: Brown and Black Carbon Emitted by a Marine Engine Operated on Heavy Fuel Oil and Distillate Fuels: Optical Properties, Size Distributions, and Emission Factors, J. Geophys. Res.-Atmos., 123, 6175-6195, https://doi.org/10.1029/2017JD027818, 2018.

Dayan, U., Ricaud, P., Zbinden, R., and Dulac, F.: Atmospheric pollution over the eastern Mediterranean during summer - a review, Atmos. Chem. Phys., 17, 13233-13263, https://doi.org/10.5194/acp-17-13233-2017, 2017.

Di Biagio, C., Formenti, P., Cazaunau, M., Pangui, E., Marchand, N., and Doussin, J.-F.: Aethalometer multiple scattering correc- tion $C_{\text {ref }}$ for mineral dust aerosols, Atmos. Meas. Tech., 10 2923-2939, https://doi.org/10.5194/amt-10-2923-2017, 2017.

Di Biagio, C., Formenti, P., Balkanski, Y., Caponi, L., Cazaunau, M., Pangui, E., Journet, E., Nowak, S., Andreae, M. O., Kandler, K., Saeed, T., Piketh, S., Seibert, D., Williams, E., and Doussin, J.-F.: Complex refractive indices and single-scattering albedo of global dust aerosols in the shortwave spectrum and relationship to size and iron content, Atmos. Chem. Phys., 19, 15503-15531, https://doi.org/10.5194/acp-19-15503-2019, 2019.

Drinovec, L., Močnik, G., Zotter, P., Prévôt, A. S. H., Ruckstuhl, C., Coz, E., Rupakheti, M., Sciare, J., Müller, T., Wiedensohler, A., and Hansen, A. D. A.: The "dual-spot" Aethalometer: an improved measurement of aerosol black carbon with realtime loading compensation, Atmos. Meas. Tech., 8, 1965-1979, https://doi.org/10.5194/amt-8-1965-2015, 2015.

Drinovec, L., Gregorič, A., Zotter, P., Wolf, R., Bruns, E. A., Prévôt, A. S. H., Petit, J.-E., Favez, O., Sciare, J., Arnold, I. J., Chakrabarty, R. K., Moosmüller, H., Filep, A., and Močnik, G.: The filter-loading effect by ambient aerosols in filter absorption photometers depends on the coating of the sampled particles, Atmos. Meas. Tech., 10, 1043-1059, https://doi.org/10.5194/amt10-1043-2017, 2017.

Drinovec, L., Sciare, J., Stavroulas, I., Bezantakos, S., Pikridas, M., Unga, F., Savvides, C., Višić, B., Remškar, M., and Močnik, G.: A new optical-based technique for real-time measurements of mineral dust concentration in $\mathrm{PM}_{10}$ using a virtual impactor, Atmos. Meas. Tech., 13, 3799-3813, https://doi.org/10.5194/amt13-3799-2020, 2020.

Ealo, M., Alastuey, A., Ripoll, A., Pérez, N., Minguillón, M. C., Querol, X., and Pandolfi, M.: Detection of Saharan dust and biomass burning events using near-real-time intensive aerosol optical properties in the north-western Mediterranean, Atmos. Chem. Phys., 16, 12567-12586, https://doi.org/10.5194/acp-1612567-2016, 2016.

EBAS: Montsec d'Ares dataset, EBAS [data set], available at: http://ebas.nilu.no/Pages/DataSetList.aspx?key= 4F862F47EC324FD6AAFA5CD8CF6F8EFB, last access: 20 September 2021a.

EBAS: Montseny dataset, EBAS [data set], available at: $\quad$ http://ebas.nilu.no/Pages/DataSetList.aspx?key= 562F658B11934EAC92BB0A2F0CD29A40, last access: 20 September $2021 \mathrm{~b}$.

Escudero, M., Castillo, S., Querol, X., Avila, A., Alarcón, M., Viana, M. M., Alastuey, A., Cuevas, E., and Rodríguez, S.: Wet and dry African dust episodes over eastern Spain, J. Geophys. Res., 110, D18S08, https://doi.org/10.1029/2004JD004731, 2005.

Ess, M. N. and Vasilatou, K.: Characterization of a new miniCAST with diffusion flame and premixed flame options: Generation of particles with high EC content in the size range $30 \mathrm{~nm}$ to $200 \mathrm{~nm}$, Aerosol Sci. Tech., 53, 29-44, https://doi.org/10.1080/02786826.2018.1536818, 2019.

Ferrero, L., Ritter, C., Cappelletti, D., Moroni, B., Močnik, G., Mazzola, M., Lupi, A., Becagli, S., Traversi, R., Cataldi, M., Neuber, R., Vitale, V., and Bolzacchini, E.: Aerosol optical properties in the Arctic: The role of aerosol chemistry and dust composition in a closure experiment between Lidar and tethered balloon vertical profiles, Sci. Total Environ., 686, 452-467, https://doi.org/10.1016/j.scitotenv.2019.05.399, 2019. 
Forello, A. C., Bernardoni, V., Calzolai, G., Lucarelli, F., Massabò, D., Nava, S., Pileci, R. E., Prati, P., Valentini, S., Valli, G., and Vecchi, R.: Exploiting multi-wavelength aerosol absorption coefficients in a multi-time resolution source apportionment study to retrieve source-dependent absorption parameters, Atmos. Chem. Phys., 19, 11235-11252, https://doi.org/10.5194/acp-19-112352019, 2019.

Forello, A. C., Amato, F., Bernardoni, V., Calzolai, G., Canepari, S., Costabile, F., Di Liberto, L., Gualtieri, M., Lucarelli, F., Nava, S., Perrino, C., Petralia, E., Valentini, S., Valli, G., and Vecchi, R.: Gaining knowledge on source contribution to aerosol optical absorption properties and organics by receptor modelling, Atmos. Environ., 243, 117873 , https://doi.org/10.1016/j.atmosenv.2020.117873, https://doi.org/10.1016/j.atmosenv.2020.117873, 2020.

Freedman, D. and Diaconis, P.: On the histogram as a density estimator: L2 theory, Z. Wahrscheinlichkeit., 57, 453-476, https://doi.org/10.1007/BF01025868, 1981.

Gyawali, M., Arnott, W. P., Lewis, K., and Moosmüller, H.: In situ aerosol optics in Reno, NV, USA during and after the summer 2008 California wildfires and the influence of absorbing and nonabsorbing organic coatings on spectral light absorption, Atmos. Chem. Phys., 9, 8007-8015, https://doi.org/10.5194/acp-9-80072009, 2009.

Hansen, A., Rosen, H., and Novakov, T.: The aethaloemter- An instrument for the real-time measurement of optical absorption by particles, Sci. Total Environ., 36, 191-196, 1984.

IPCC; Climate Change 2001: The Scientific Basis. Contribution of Working Group I to the Third Assessment Report of the Intergovernmental Panel on Climate Change, edited by: Houghton, J. T., Ding, Y., Griggs, D. J., Noguer, M., van der Linden, P. J., Dai, X., Maskell, K., and Johnson, C. A., Cambridge University Press, Cambridge, United Kingdom and New York, NY, USA, 881 pp., 2001.

Kalivitis, N., Gerasopoulos, E., Vrekoussis, M., Kouvarakis, G., Kubilay, N., Hatzianastassiou, N., Vardavas, I., and Mihalopoulos, N.: Dust transport over the eastern Mediterranean derived from Total Ozone Mapping Spectrometer, Aerosol Robotic Network, and surface measurements, J. Geophys. Res., 112, D03202, https://doi.org/10.1029/2006JD007510, 2007.

Kirchstetter, T. W., Novakov, T., and Hobbs, P. V.: Evidence that the spectral dependence of light absorption by aerosols is affected by organic carbon, J. Geophys. Res., 109, D21208, https://doi.org/10.1029/2004JD004999, 2004.

Koçak, M., Mihalopoulos, N., and Kubilay, N.: Contributions of natural sources to high $\mathrm{PM}_{10}$ and $\mathrm{PM}_{2.5}$ events in the eastern Mediterranean, Atmos. Environ., 41, 3806-3818, 2007.

Lack, D. A., Lovejoy, E. R., Baynard, T., Pettersson, A., and Ravishankara, A. R.: Aerosol Absorption Measurement using Photoacoustic Spectroscopy: Sensitivity, Calibration, and Uncertainty Developments, Aerosol Sci. Tech., 40, 697-708, https://doi.org/10.1080/02786820600803917, 2006.

Lack, D. A., Cappa, C. D., Covert, D. S., Baynard, T., Massoli, P., Sierau, B., Bates, T. S., Quinn, P. K., Lovejoy, E. R., and Ravishankara, A. R.: Bias in filter-based aerosol light absorption measurements due to organic aerosol loading: Evidence from ambient measurements, Aerosol Sci. Tech., 42, 1033-1041, https://doi.org/10.1080/02786820802389277, 2008.
Lack, D. A., Moosmüller, H., McMeeking, G. R., Chakrabarty, R. K., and Baumgardner, D.: Characterizing elemental, equivalent black, and refractory black carbon aerosol particles: A review of techniques, their limitations and uncertainties, Anal. Bioanal. Chem., 406, 99-122, https://doi.org/10.1007/s00216013-7402-3, 2014.

Laing, J. R., Jaffe, D. A., and Sedlacek, A. J.: Comparison of filter-based absorption measurements of biomass burning aerosol and background aerosol at the Mt. Bachelor observatory, Aerosol Air Qual. Res., 20, 663-678, https://doi.org/10.4209/aaqr.2019.06.0298, 2020.

Laj, P., Bigi, A., Rose, C., Andrews, E., Lund Myhre, C., Collaud Coen, M., Lin, Y., Wiedensohler, A., Schulz, M., Ogren, J. A., Fiebig, M., Gliß, J., Mortier, A., Pandolfi, M., Petäja, T., Kim, S.-W., Aas, W., Putaud, J.-P., Mayol-Bracero, O., Keywood, M., Labrador, L., Aalto, P., Ahlberg, E., Alados Arboledas, L., Alastuey, A., Andrade, M., Artíñano, B., Ausmeel, S., Arsov, T., Asmi, E., Backman, J., Baltensperger, U., Bastian, S., Bath, O., Beukes, J. P., Brem, B. T., Bukowiecki, N., Conil, S., Couret, C., Day, D., Dayantolis, W., Degorska, A., Eleftheriadis, K., Fetfatzis, P., Favez, O., Flentje, H., Gini, M. I., Gregorič, A., GyselBeer, M., Hallar, A. G., Hand, J., Hoffer, A., Hueglin, C., Hooda, R. K., Hyvärinen, A., Kalapov, I., Kalivitis, N., Kasper-Giebl, A., Kim, J. E., Kouvarakis, G., Kranjc, I., Krejci, R., Kulmala, M., Labuschagne, C., Lee, H.-J., Lihavainen, H., Lin, N.-H., Löschau, G., Luoma, K., Marinoni, A., Martins Dos Santos, S., Meinhardt, F., Merkel, M., Metzger, J.-M., Mihalopoulos, N., Nguyen, N. A., Ondracek, J., Pérez, N., Perrone, M. R., Petit, J.-E., Picard, D., Pichon, J.-M., Pont, V., Prats, N., Prenni, A., Reisen, F., Romano, S., Sellegri, K., Sharma, S., Schauer, G., Sheridan, P., Sherman, J. P., Schütze, M., Schwerin, A., Sohmer, R., Sorribas, M., Steinbacher, M., Sun, J., Titos, G., Toczko, B., Tuch, T., Tulet, P., Tunved, P., Vakkari, V., Velarde, F., Velasquez, P., Villani, P., Vratolis, S., Wang, S.-H., Weinhold, K., Weller, R., Yela, M., Yus-Diez, J., Zdimal, V., Zieger, P., and Zikova, N.: A global analysis of climate-relevant aerosol properties retrieved from the network of Global Atmosphere Watch (GAW) near-surface observatories, Atmos. Meas. Tech., 13, 4353-4392, https://doi.org/10.5194/amt-13-4353-2020, 2020.

Laskin, A., Laskin, J., and Nizkorodov, S. A.: Chemistry of Atmospheric Brown Carbon, Chem. Rev., 115, 4335-4382, https://doi.org/10.1021/cr5006167, 2015.

Lee, J. and Moosmüller, H.: Measurement of light absorbing aerosols with folded-jamin photothermal interferometry, Sensors, 20, 1-13, https://doi.org/10.3390/s20092615, 2020.

Lin, C. I., Baker, M., and Charlson, R. J.: Absorption Coefficient of Atmospheric Aerosol: a Method for Measurement, Appl. Optics, 12, 1356-1363, 1973.

Linke, C., Ibrahim, I., Schleicher, N., Hitzenberger, R., Andreae, M. O., Leisner, T., and Schnaiter, M.: A novel singlecavity three-wavelength photoacoustic spectrometer for atmospheric aerosol research, Atmos. Meas. Tech., 9, 5331-5346, https://doi.org/10.5194/amt-9-5331-2016, 2016.

Liousse, C., Cachier, H., and Jennings, S. G.: Optical and thermal measurements of black carbon aerosol content in different environments: Variation of the specific attenuation cross-section, sigma $(\sigma)$, Atmospheric Environment A-Gen., 27, 1203-1211, https://doi.org/10.1016/0960-1686(93)90246-U, 1993. 
Liu, S., Aiken, A. C., Gorkowski, K., Dubey, M. K., Cappa, C. D., Williams, L. R., Herndon, S. C., Massoli, P., Fortner, E. C., Chhabra, P. S., Brooks, W. A., Onasch, T. B., Jayne, J. T., Worsnop, D. R., China, S., Sharma, N., Mazzoleni, C., Xu, L., Ng, N. L., Liu, D., Allan, J. D., Lee, J. D., Fleming, Z. L., Mohr, C., Zotter, P., Szidat, S., and Prévôt, A. S.: Enhanced light absorption by mixed source black and brown carbon particles in UK winter, Nat. Commun., 6, 8435, https://doi.org/10.1038/ncomms9435, 2015.

Lyamani, H., Olmo, F., Alcántara, A., and Alados-Arboledas, L.: Atmospheric aerosols during the 2003 heat wave in southeastern Spain II: Microphysical columnar properties and radiative forcing, Atmos. Environ., 40, 6465-6476, 2006.

Massabò, D., Bernardoni, V., Bove, M. C., Brunengo, A., Cuccia, E., Piazzalunga, A., Prati, P., Valli, G., and Vecchi, R.: A multi-wavelength optical set-up for the characterization of carbonaceous particulate matter, J. Aerosol Sci., 60, 34-46, https://doi.org/10.1016/j.jaerosci.2013.02.006, 2013.

Mengis, N. and Matthews, H. D.: Non- $\mathrm{CO}_{2}$ forcing changes will likely decrease the remaining carbon budget for $1.5^{\circ} \mathrm{C}$, npj Climate and Atmospheric Science, 3, 1-7, https://doi.org/10.1038/s41612-020-0123-3, 2020.

Mona, L., Amodeo, A., Pandolfi, M., and Pappalardo, G.: Saharan dust intrusions in the Mediterranean area: Three years of Raman lidar measurements, J. Geophys. Res., 111, D16203, https://doi.org/10.1029/2005JD006569, 2006.

Moosmüller, H., Chakrabarty, R. K., and Arnott, W. P.: Aerosol light absorption and its measurement: A review, J. Quant. Spectrosc. Ra., 110, 844-878, https://doi.org/10.1016/j.jqsrt.2009.02.035, 2009.

Müller, T.: Development of correction factors for Aethalometers AE31 and AE33, ACTRIS-2 WP3 Workshop, Athens, 10-12 November 2015.

Müller, T., Henzing, J. S., de Leeuw, G., Wiedensohler, A., Alastuey, A., Angelov, H., Bizjak, M., Collaud Coen, M., Engström, J. E., Gruening, C., Hillamo, R., Hoffer, A., Imre, K., Ivanow, P., Jennings, G., Sun, J. Y., Kalivitis, N., Karlsson, H., Komppula, M., Laj, P., Li, S.-M., Lunder, C., Marinoni, A., Martins dos Santos, S., Moerman, M., Nowak, A., Ogren, J. A., Petzold, A., Pichon, J. M., Rodriquez, S., Sharma, S., Sheridan, P. J., Teinilä, K., Tuch, T., Viana, M., Virkkula, A., Weingartner, E., Wilhelm, R., and Wang, Y. Q.: Characterization and intercomparison of aerosol absorption photometers: result of two intercomparison workshops, Atmos. Meas. Tech., 4, 245-268, https://doi.org/10.5194/amt-4-245-2011, 2011a.

Müller, T., Laborde, M., Kassell, G., and Wiedensohler, A.: Design and performance of a three-wavelength LED-based total scatter and backscatter integrating nephelometer, Atmos. Meas. Tech., 4, 1291-1303, https://doi.org/10.5194/amt-4-1291-2011, $2011 \mathrm{~b}$.

Myhre, G., Shindell, D., Breéon, F.-M., Collins, W., Fuglestvedt, J., Huang, J., Koch, D., Lamarque, J.-F., Lee, D., Mendoza, B., Nakajima, T., Robock, A., Stephens, G., Takemura, T., and Zhang, H.: Anthropogenic and Natural Radiative Forcing, 8, 659-740, Cambridge University Press, Cambridge, United Kingdom and New York, NY, USA, https://doi.org/10.1017/CBO9781107415324.018, 2013.

Ogren, J. A., Wendell, J., Andrews, E., and Sheridan, P. J.: Continuous light absorption photometer for long-term studies, At- mos. Meas. Tech., 10, 4805-4818, https://doi.org/10.5194/amt10-4805-2017, 2017.

Onasch, T. B., Massoli, P., Kebabian, P. L., Hills, F. B., Bacon, F. W., and Freedman, A.: Single scattering albedo monitor for airborne particulates, Aerosol Sci. Tech., 49, 267-279, https://doi.org/10.1080/02786826.2015.1022248, 2015.

Pandolfi, M., Cusack, M., Alastuey, A., and Querol, X.: Variability of aerosol optical properties in the Western Mediterranean Basin, Atmos. Chem. Phys., 11, 8189-8203, https://doi.org/10.5194/acp-11-8189-2011, 2011.

Pandolfi, M., Ripoll, A., Querol, X., and Alastuey, A.: Climatology of aerosol optical properties and black carbon mass absorption cross section at a remote high-altitude site in the western Mediterranean Basin, Atmos. Chem. Phys., 14, 6443-6460, https://doi.org/10.5194/acp-14-6443-2014, 2014a.

Pandolfi, M., Tobias, A., Alastuey, A., Sunyer, J., Schwartz, J., Lorente, J., Pey, J., and Querol, X.: Effect of atmospheric mixing layer depth variations on urban air quality and daily mortality during Saharan dust outbreaks, Sci. Total Environ., 494, 283289, 2014b.

Pandolfi, M., Alados-Arboledas, L., Alastuey, A., Andrade, M., Angelov, C., Artiñano, B., Backman, J., Baltensperger, U., Bonasoni, P., Bukowiecki, N., Collaud Coen, M., Conil, S., Coz, E., Crenn, V., Dudoitis, V., Ealo, M., Eleftheriadis, K., Favez, O., Fetfatzis, P., Fiebig, M., Flentje, H., Ginot, P., Gysel, M., Henzing, B., Hoffer, A., Holubova Smejkalova, A., Kalapov, I., Kalivitis, N., Kouvarakis, G., Kristensson, A., Kulmala, M., Lihavainen, H., Lunder, C., Luoma, K., Lyamani, H., Marinoni, A., Mihalopoulos, N., Moerman, M., Nicolas, J., O’Dowd, C., Petäjä, T., Petit, J.-E., Pichon, J. M., Prokopciuk, N., Putaud, J.P., Rodríguez, S., Sciare, J., Sellegri, K., Swietlicki, E., Titos, G., Tuch, T., Tunved, P., Ulevicius, V., Vaishya, A., Vana, M., Virkkula, A., Vratolis, S., Weingartner, E., Wiedensohler, A., and Laj, P.: A European aerosol phenomenology - 6: scattering properties of atmospheric aerosol particles from 28 ACTRIS sites, Atmos. Chem. Phys., 18, 7877-7911, https://doi.org/10.5194/acp18-7877-2018, 2018.

Park, S. S., Hansen, A. D., and Cho, S. Y.: Measurement of real time black carbon for investigating spot loading effects of Aethalometer data, Atmos. Environ., 44, 1449-1455, https://doi.org/10.1016/j.atmosenv.2010.01.025, 2010.

Pérez, N., Pey, J., Castillo, S., Viana, M., Alastuey, A., and Querol, $\mathrm{X}$.: Interpretation of the variability of levels of regional background aerosols in the Western Mediterranean, Sci. Total Environ., 407, 527-540, 2008.

Petzold, A. and Schönlinner, M.: Multi-angle absorption photometry-a new method for the measurement of aerosol light absorption and atmospheric black carbon, J. Aerosol Sci., 35, 421-441, 2004.

Petzold, A., Schloesser, H., Sheridan, P. J., Arnott, W. P., Ogren, J. A., and Virkkula, A.: Evaluation of multiangle absorption photometry for measuring aerosol light absorption, Aerosol Sci. Tech., 39, 40-51, https://doi.org/10.1080/027868290901945, 2005.

Petzold, A., Ogren, J. A., Fiebig, M., Laj, P., Li, S.-M., Baltensperger, U., Holzer-Popp, T., Kinne, S., Pappalardo, G., Sugimoto, N., Wehrli, C., Wiedensohler, A., and Zhang, X.-Y.: Recommendations for reporting "black carbon" measurements, At- 
mos. Chem. Phys., 13, 8365-8379, https://doi.org/10.5194/acp13-8365-2013, 2013.

Pey, J., Pérez, N., Castillo, S., Viana, M., Moreno, T., Pandolfi, M., López-Sebastián, J., Alastuey, A., and Querol, X.: Geochemistry of regional background aerosols in the Western Mediterranean, Atmos. Res., 94, 422-435, 2009.

Pey, J., Querol, X., Alastuey, A., Forastiere, F., and Stafoggia, M.: African dust outbreaks over the Mediterranean Basin during 2001-2011: $\mathrm{PM}_{10}$ concentrations, phenomenology and trends, and its relation with synoptic and mesoscale meteorology, Atmos. Chem. Phys., 13, 1395-1410, https://doi.org/10.5194/acp13-1395-2013, 2013.

Querol, X., Alastuey, A., Puicercus, J. A., Mantilla, E., Miro, J. V., Lopez-Soler, A., Plana, F., and Artiñano, B.: Seasonal evolution of suspended particles around a large coal-fired power station: particulate levels and sources, Atmos. Environ., 32, 1963-1978, 1998.

Querol, X., Alastuey, A., Rodriguez, S., Plana, F., Ruiz, C. R., Cots, N., Massagué, G., and Puig, O.: $\mathrm{PM}_{10}$ and $\mathrm{PM}_{2.5}$ source apportionment in the Barcelona Metropolitan area, Catalonia, Spain, Atmos. Environ., 35, 6407-6419, 2001.

Querol, X., Alastuey, A., Viana, M. M., Rodriguez, S., Artíñano, B., Salvador, P., Do Santos, S. G., Fernandez Patier, R., Ruiz, C., De la Rosa, J., Sanchez de la Campa, A., Menendez, M., and Gil, J.: Speciation and origin of $\mathrm{PM}_{10}$ and $\mathrm{PM}_{2.5}$ in Spain, J. Aerosol Sci., 35, 1151-1172, 2004.

Querol, X., Alastuey, A., Pey, J., Cusack, M., Pérez, N., Mihalopoulos, N., Theodosi, C., Gerasopoulos, E., Kubilay, N., and Koçak, M.: Variability in regional background aerosols within the Mediterranean, Atmos. Chem. Phys., 9, 4575-4591, https://doi.org/10.5194/acp-9-4575-2009, 2009a.

Querol, X., Pey, J., Pandolfi, M., Alastuey, A., Cusack, M., Pérez, N., Moreno, T., Viana, M., Mihalopoulos, N., Kallos, G., and Kleanthous, S.: African dust contributions to mean ambient $\mathrm{PM}_{10}$ mass-levels across the Mediterranean Basin, Atmos. Environ., 43, 4266-4277, 2009b.

Querol, X., Perez, N., Reche, C., Ealo, M., Ripoll, A., Tur, J., Pandolfi, M., Pey, J., Salvador, P., Moreno, T., and Alastuey, A.: African dust and air quality over Spain: Is it only dust that matters?, Sci. Total Environ., 686, 737-752, 2019.

Ramanathan, V. and Carmichael, G.: Global and regional climate changes due to black carbon, Nat. Geosci., 1, 221-227, https://doi.org/10.1038/ngeo156, 2008.

Ramanathan, V., Crutzen, P., Kiehl, J., and Rosenfeld, D.: Aerosols, climate, and the hydrological cycle, Science, 294, 2119-2124, 2001.

Reche, C., Querol, X., Alastuey, A., Viana, M., Pey, J., Moreno, T., Rodríguez, S., González, Y., Fernández-Camacho, R., de la Rosa, J., Dall'Osto, M., Prévôt, A. S. H., Hueglin, C., Harrison, R. M., and Quincey, P.: New considerations for PM, Black Carbon and particle number concentration for air quality monitoring across different European cities, Atmos. Chem. Phys., 11, 6207-6227, https://doi.org/10.5194/acp-11-6207-2011, 2011.

Rigler, M., Drinovec, L., Lavrič, G., Vlachou, A., Prévôt, A. S. H., Jaffrezo, J. L., Stavroulas, I., Sciare, J., Burger, J., Kranjc, I., Turšič, J., Hansen, A. D. A., and Močnik, G.: The new instrument using a TC-BC (total carbon-black carbon) method for the online measurement of carbonaceous aerosols, Atmos.
Meas. Tech., 13, 4333-4351, https://doi.org/10.5194/amt-134333-2020, 2020.

Ripoll, A., Pey, J., Minguillón, M. C., Pérez, N., Pandolfi, M., Querol, X., and Alastuey, A.: Three years of aerosol mass, black carbon and particle number concentrations at Montsec (southern Pyrenees, 1570 ma.s.1.), Atmos. Chem. Phys., 14, 4279-4295, https://doi.org/10.5194/acp-14-4279-2014, 2014.

Ripoll, A., Minguillón, M. C., Pey, J., Jimenez, J. L., Day, D. A., Sosedova, Y., Canonaco, F., Prévôt, A. S. H., Querol, X., and Alastuey, A.: Long-term real-time chemical characterization of submicron aerosols at Montsec (southern Pyrenees, $1570 \mathrm{~m}$ a.s.1.), Atmos. Chem. Phys., 15, 2935-2951, https://doi.org/10.5194/acp-15-2935-2015, 2015.

Rivas, I., Beddows, D. C. S., Amato, F., Green, D. C., Järvi, L., Hueglin, C., Reche, C., Timonen, H., Fuller, G. W., Niemi, J. V., Pérez, N., Aurela, M., Hopke, P. K., Alastuey, A., Kulmala, M., Harrison, R. M., Querol, X., and Kelly, F. J.: Source apportionment of particle number size distribution in urban background and traffic stations in four European cities, Environ. Int., 135, 105345, https://doi.org/10.1016/j.envint.2019.105345, 2020.

Rodriguez, S., Querol, X., Alastuey, A., Kallos, G., and Kakaliagou, O.: Saharan dust contributions to $\mathrm{PM}_{10}$ and TSP levels in Southern and Eastern Spain, Atmos. Environ., 35, 2433-2447, 2001.

Rodríguez, S., Querol, X., Alastuey, A., and Plana, F.: Sources and processes affecting levels and composition of atmospheric aerosol in the western Mediterranean, J. Geophys. Res., 107, 4777, https://doi.org/10.1029/2001JD001488, 2002.

Samset, B. H., Sand, M., Smith, C. J., Bauer, S. E., Forster, P. M., Fuglestvedt, J. S., Osprey, S., and Schleussner, C. F.: Climate Impacts From a Removal of Anthropogenic Aerosol Emissions, Geophys. Res. Lett., 45, 1020-1029, https://doi.org/10.1002/2017GL076079, 2018.

Sandradewi, J., Prévôt, A. S., Szidat, S., Perron, N., Alfarra, M. R., Lanz, V. A., Weingartner, E., and Baltensperger, U. R.: Using aerosol light absorption measurements for the quantitative determination of wood burning and traffic emission contribution to particulate matter, Environ. Sci. Technol., 42, 3316-3323, https://doi.org/10.1021/es702253m, 2008.

Schauer, G., Kasper-Giebl, A., and Močnik, G.: Increased PM concentrations during a combined wildfire and saharan dust event observed at high-altitude Sonnblick observatory, Austria, Aerosol Air Qual. Res., 16, 542-554, https://doi.org/10.4209/aaqr.2015.05.0337, 2016.

Schmeisser, L., Backman, J., Ogren, J. A., Andrews, E., Asmi, E., Starkweather, S., Uttal, T., Fiebig, M., Sharma, S., Eleftheriadis, K., Vratolis, S., Bergin, M., Tunved, P., and Jefferson, A.: Seasonality of aerosol optical properties in the Arctic, Atmos. Chem. Phys., 18, 11599-11622, https://doi.org/10.5194/acp-18-115992018, 2018.

Schmid, O., Artaxo, P., Arnott, W. P., Chand, D., Gatti, L. V., Frank, G. P., Hoffer, A., Schnaiter, M., and Andreae, M. O.: Spectral light absorption by ambient aerosols influenced by biomass burning in the Amazon Basin. I: Comparison and field calibration of absorption measurement techniques, Atmos. Chem. Phys., 6, 3443-3462, https://doi.org/10.5194/acp-6-3443-2006, 2006.

Segura, S., Estellés, V., Titos, G., Lyamani, H., Utrillas, M. P., Zotter, P., Prévôt, A. S. H., Močnik, G., Alados-Arboledas, L., and Martínez-Lozano, J. A.: Determination and analysis of in situ spectral aerosol optical properties by a multi- 
instrumental approach, Atmos. Meas. Tech., 7, 2373-2387, https://doi.org/10.5194/amt-7-2373-2014, 2014.

Sheridan, P. J., Patrick Arnott, W., Ogren, J. A., Andrews, E., Atkinson, D. B., Covert, D. S., Moosmüller, H., Petzold, A., Schmid, B., Strawa, A. W., Varma, R., and Virkkula, A.: The reno aerosol optics study: An evaluation of aerosol absorption measurement methods, Aerosol Sci. Tech., 39, 1-16, https://doi.org/10.1080/027868290901891, 2005.

Singh, S., Fiddler, M. N., Smith, D., and Bililign, S.: Error analysis and uncertainty in the determination of aerosol optical properties using cavity ring-down spectroscopy, integrating nephelometry, and the extinction-minus-scattering method, Aerosol Sci. Tech., 48, 1345-1359, https://doi.org/10.1080/02786826.2014.984062, 2014.

Sokolik, I. N. and Toon, O. B.: Incorporation of mineralogical composition into models of the radiative properties of mineral aerosol from UV to IR wavelengths, J. Geophys. Res.-Atmos., 104, 9423-9444, https://doi.org/10.1029/1998JD200048, 1999.

Springston, S. R. and Sedlacek, A. J.: Noise characteristics of an instrumental particle absorbance technique, Aerosol Sci. Tech., 41, 1110-1116, https://doi.org/10.1080/02786820701777457, 2007.

Stephens, M., Turner, N., and Sandberg, J.: Particle identification by laser-induced incandescence in a solid-state laser cavity, Appl. Optics, 42, 3726, https://doi.org/10.1364/ao.42.003726, 2003.

Terhune, R. W. and Anderson, J. E.: Spectrophone measurements of the absorption of visible light by aerosols in the atmosphere, Opt. Lett., 1, 70, https://doi.org/10.1364/ol.1.000070, 1977.

Valentini, S., Barnaba, F., Bernardoni, V., Calzolai, G., Costabile, F., Di Liberto, L., Forello, A. C., Gobbi, G. P., Gualtieri, M., Lucarelli, F., Nava, S., Petralia, E., Valli, G., Wiedensohler, A., and Vecchi, R.: Classifying aerosol particles through the combination of optical and physical-chemical properties: Results from a wintertime campaign in Rome (Italy), Atmos. Res., 235, 104799 , https://doi.org/10.1016/j.atmosres.2019.104799, 2020a.

Valentini, S., Bernardoni, V., Bolzacchini, E., Ciniglia, D., Pandolfi, M., Ferrero, L., Forello, A. C., Massabó, D., Pandolfi, M., Prati, P., Soldan, F., Valli, G., Yus-díez, J., and Vecchi, R.: Applicability of benchtop multi-wavelength polar photometers to off-line measurements of the Multi-Angle Absorption Photometer, 152, 105701, https://doi.org/10.1016/j.jaerosci.2020.105701, $2020 \mathrm{~b}$.

Vecchi, R., Bernardoni, V., Paganelli, C., and Valli, G.: A filterbased light-absorption measurement with polar photometer: Effects of sampling artefacts from organic carbon, J. Aerosol Sci., 70, 15-25, 2014.

Virkkula, A., Mäkelä, T., Hillamo, R., Yli-Tuomi, T., Hirsikko, A., Hämeri, K., and Koponen, I. K.: A simple procedure for correcting loading effects of aethalometer data, J. Air Waste Manage., 57, 1214-1222, https://doi.org/10.3155/1047-3289.57.10.1214, 2007.

Virkkula, A., Chi, X., Ding, A., Shen, Y., Nie, W., Qi, X., Zheng, L., Huang, X., Xie, Y., Wang, J., Petäjä, T., and Kulmala, M.: On the interpretation of the loading correction of the aethalometer, Atmos. Meas. Tech., 8, 4415-4427, https://doi.org/10.5194/amt8-4415-2015, 2015.
Visser, B., Röhrbein, J., Steigmeier, P., Drinovec, L., Močnik, G., and Weingartner, E.: A single-beam photothermal interferometer for in situ measurements of aerosol light absorption, Atmos. Meas. Tech., 13, 7097-7111, https://doi.org/10.5194/amt13-7097-2020, 2020.

Wang, Y., Le, T., Chen, G., Yung, Y. L., Su, H., Seinfeld, J. H., and Jiang, J. H.: Reduced European aerosol emissions suppress winter extremes over northern Eurasia, Nat. Clim. Change, 10, 225-230, https://doi.org/10.1038/s41558-020-0693-4, 2020.

Weingartner, E., Saathoff, H., Schnaiter, M., Streit, N., Bitnar, B., and Baltensperger, U.: Absorption of light by soot particles: Determination of the absorption coefficient by means of aethalometers, J. Aerosol Sci., 34, 1445-1463, https://doi.org/10.1016/S0021-8502(03)00359-8, 2003.

World Meteorological Organization: WMO/GAW Aerosol Measurement Procedures, Guidelines and Recommendations, 2nd edn., GAW Report No. 227, WMO Report No. 1177, ISBN 97892-63-11177-7, available at: https://library.wmo.int/opac/doc_ num.php?explnum_id=3073 (last access: 20 September 2021), 2016.

Yus-Díez, J., Ealo, M., Pandolfi, M., Perez, N., Titos, G., Močnik, G., Querol, X., and Alastuey, A.: Aircraft vertical profiles during summertime regional and Saharan dust scenarios over the north-western Mediterranean basin: aerosol optical and physical properties, Atmos. Chem. Phys., 21, 431-455, https://doi.org/10.5194/acp-21-431-2021, 2021.

Zanatta, M., Gysel, M., Bukowiecki, N., Müller, T., Weingartner, E., Areskoug, H., Fiebig, M., Yttri, K. E., Mihalopoulos, N., Kouvarakis, G., Beddows, D., Harrison, R. M., Cavalli, F., Putaud, J. P., Spindler, G., Wiedensohler, A., Alastuey, A., Pandolfi, M., Sellegri, K., Swietlicki, E., Jaffrezo, J. L., Baltensperger, U., and Laj, P.: A European aerosol phenomenology-5: Climatology of black carbon optical properties at 9 regional background sites across Europe, Atmos. Environ., 145, 346-364, 2016.

Zhang, Y., Favez, O., Canonaco, F., Liu, D., Močnik, G., Amodeo, T., Sciare, J., Prévôt, A. S. H., Gros, V., and Albinet, A.: Evidence of major secondary organic aerosol contribution to lensing effect black carbon absorption enhancement, npj Climate and Atmospheric Science, 1, 47, https://doi.org/10.1038/s41612-0180056-2, 2018.

Zotter, P., Herich, H., Gysel, M., El-Haddad, I., Zhang, Y., Močnik, G., Hüglin, C., Baltensperger, U., Szidat, S., and Prévôt, A. S. H.: Evaluation of the absorption Ångström exponents for traffic and wood burning in the Aethalometer-based source apportionment using radiocarbon measurements of ambient aerosol, Atmos. Chem. Phys., 17, 4229-4249, https://doi.org/10.5194/acp17-4229-2017, 2017. 